\title{
IMPACTO ECONÓMICO DE LAS ACCIONES DE TUTELA EN SALUD EN COLOMBIA*
}

\author{
ECONOMIC IMPACT OF HEALTH \\ CARE ACTIONS IN COLOMBIA
}

\author{
Clara Viviana Plazas-Gómez** \\ Diego Mauricio Moreno-Guzmán****
}

Fecha de recepción: 2 de febrero de 2017

Fecha de aceptación: 29 de marzo de 2017

Disponible en linea: 30 de noviembre de 2017

\section{Para citar este artículo/To cite this article}

\begin{abstract}
Plazas-Gómez, Clara Viviana \& Moreno Guzmán, Diego Mauricio, Impacto económico de las acciones de tutela en salud en Colombia, 135 Vniversitas, 325-376 (2017). https://doi.org/10.11144/Javeriana.vj135.ieat
\end{abstract}

doi: 10.11144/Javeriana.vj135.ieat

* Este artículo es fruto de las reflexiones de investigación del proyecto de investigación de La progresividad del gasto público social y su impacto sobre el derecho a la salud, del Área de Hacienda pública y Derecho tributario. Esperamos avanzar en la búsqueda de la eficiente garantía del derecho fundamental a la salud para un equilibrio de las finanzas públicas. Artículo ganador del XXIX Concurso José Ignacio de Márquez que utiliza metodologías y criterios propios del análisis económico del derecho, septiembre de 2017.

** Abogada, Universidad del Rosario. Orcid: 000-0002-4719-6624. Especialista en derecho tributario, Universidad del Rosario. Magíster (DEA) en derecho público, Universidad de Jaén, España. Candidata a doctora en derecho público, Universidad de Jaén, UJA, España. Profesora de derecho tributario, Facultad de Jurisprudencia, Universidad del Rosario. Docente en la especialización de derecho tributario y gerencia pública y control fiscal, Universidad del Rosario. Investigadora y directora de proyectos de investigación como La progresividad del gasto público social y su impacto sobre el derecho a la salud y Política fiscal desde la perspectiva de género. Consultora y asesora de empresas. Actualmente, directora del sector movilidad, Contraloría de Bogotá. Contacto: clara. plazas@urosario.edu.co

*** Estudiante de jurisprudencia, Facultad de Jurisprudencia, Universidad del Rosario, en proceso de grado y con profundización en derecho administrativo y comercial. Orcid: 0000-0002- 2005-9961. Miembro de la línea de investigación en hacienda pública y derecho tributario, Universidad del Rosario. Monitor académico de la asignatura derecho tributario, Universidad del Rosario. Candidato a colegial de número, Universidad del Rosario. Contacto: diegomauriciomg@gmail.com 


\section{RESUMEN}

En Colombia, la Constitución Política de 1991 adoptó el modelo político de Estado social de derecho y el reconocimiento de los derechos fundamentales o derechos sociales. Este artículo tiene por objetivo revisar y analizar cómo el uso de la acción de tutela con miras a garantizar el derecho a la salud, se incrementó considerablemente durante la primera década de la vigencia de la Constitución, esta situación se ha mantenido en los últimos años, como consecuencia de las falencias y debilidades del Sistema General de Seguridad Social en Salud (SGSSS), establecido por la Ley 100 de 1993. Esto ha generado un impacto económico en las finanzas públicas, además de la división dogmática en el país, por lo que se conoce como activismo de la Corte Constitucional, de cara a las decisiones y órdenes impartidas, con contenido económico y presupuestal.

Palabras clave: Derecho a la salud; acción de tutela; Plan Obligatorio de Salud (POS); reclamaciones por POS y NO-POS; enfermedades de alto costo; sostenibilidad fiscal; efectos económicos 


\section{ABSTRACT}

The Colombian Politic Constitution of 1991 adopted the politic model of social state of law and recognized the fundamental and social rights. This article is to review and analyze the way how the constitutional action called Acción de tutela, to protect the health right, has increased in a really high proportion in the first decade of Constitution validity, this situation hasn't changed in the last years, as a consequence of the failures and weakness of the General System of Social Security of Health (SGSSS) established by the Law 100 of 1993. This specific situation has caused an economical impact in the public finances, besides the dogmatic division inside the country, this is called by the Constitutional Court as activism, because all the orders and decision has an economic and budgetary content.

Keywords: Health right; constitutional action called acción de tutela; obligatory health system (POS); reclaims by the POS and NO POS; disease of high cost; fiscal sustainability; economic effects

\section{SUMARIO}

INTRODUCCIÓN.- I. LA FÓRMULA DEL ESTADO SOCIAL DE DERECHO COMO ANTESALA DEL DERECHO A LA SALUd EN COLOMBiA.- II. ANÁlisis ECoNómico DE Las DeCisiones De TUtela EN SAlud.- $A$. Acción de tutela y Plan Obligatorio de Salud (POS).- B. Acciones de tutela y enfermedades de alto costo.- $C$. Recobros al Fondo de Solidaridad y garantías (Fosyga).- III. Tutelas en SALUd: ENTRE El GARANTISMO Y El aCtivismo.- ConClusión.- Bibliografía. 


\section{INTRODUCCIÓN}

La salud en Colombia es el segundo derecho más accionado por medio de la tutela ${ }^{1}$, lo que convierte esta acción en el mecanismo idóneo para su protección. Pero, a su vez, en el punto de inicio de la controversia por las implicaciones económicas y presupuestales, como consecuencia de las acciones administrativas ordenadas por la Corte Constitucional.

El uso de la acción de tutela como mecanismo para reclamar situaciones vinculadas directamente con la salud - reclamaciones por medicamentos y servicios incluidos dentro del Plan Obligatorio de Salud (POS), los costos de tratamiento en enfermedades de alto costo y la financiación de la salud - , tuvo un notorio crecimiento entre 1999 y 2015, al pasar de 21.301 a 151.213 acciones $^{2}$, por el deficiente funcionamiento del Sistema de Salud, generado por la negación en la prestación de los servicios en muchos de los casos.

Esta problemática se desarrollará a lo largo del presente escrito bajo una visión jurídica-económica, pasando por transformaciones conceptuales referentes a la protección del derecho y el activismo judicial, que ha abierto la puerta al debate, que para algunos debe procurar materializar el derecho a la salud, por tratarse de un derecho humano y, para otros, debe poner límite a la intervención de la Corte Constitucional por sus implicaciones presupuestales.

\section{LA FÓRMULA DEL ESTADO SOCIAL DE DERECHO COMO ANTESALA DEL DERECHO A LA SALUd EN COLOMBIA}

Con la Constitución Política de 1991 se implementó el Estado Social de Derecho, que se identifica con los valores y fines enunciados en el Preámbulo de la Carta, de tal suerte que las normas constitucionales que soportan esta estructura política, se orientan hacia la protección de la persona humana y de su dignidad ${ }^{3}$, con el fin

1 Colombia, Defensoría del Pueblo. La tutela y los derechos a la salud y a la seguridad social, 2015 (Defensoría del Pueblo, Bogotá, 2016).

2 Colombia, Defensoría del Pueblo. La tutela y los derechos a la salud y a la seguridad social, 2015 (Defensoría del Pueblo, Bogotá, 2016).

3 Colombia, Corte Constitucional, Sentencia T-533-92, 23 de septiembre de 1992, magistrado ponente Eduardo Cifuentes-Muñoz. Disponible en: http://www.corteconstitucional.gov.co/ relatoria/1992/t-533-92.htm 
de alcanzar la igualdad material. En este escenario, el Estado está obligado a garantizar los derechos sociales, por medio de la legislación y de la creación de políticas públicas de protección social, bajo los presupuestos de la preservación a plenitud de los derechos y libertades y definir la naturaleza del régimen político, económico y social. Esto implica que el Estado no asume únicamente deberes de abstención, sino que, además, en su cabeza radican obligaciones de hacer, como la garantía de condiciones mínimas de existencia para toda su población ${ }^{4}$.

Se incorporaron los Derechos Económicos, Sociales y Culturales (DESC) $)^{5}$, entendidos como derechos prestacionales o de segunda generación, que deben ser suministrados por el Estado ${ }^{6}$, que requieren una organización estatal, el apoyo social, un conjunto de actitudes cívicas y un compromiso democrático serio ${ }^{7}$. Estos derechos cumplen una finalidad en doble sentido, con obligaciones positivas y obligaciones negativas, las primeras de ellas relacionadas con la abstención de realizar ciertas actividades por parte del Estado u obligaciones de no hacer y las obligaciones positivas consistentes en obligaciones de hacer, que para su materialización requiere que el Estado disponga de los fondos suficientes para cumplir ${ }^{8}$, su propósito es lograr la igualdad real y mejorar las condiciones materiales e inmateriales de vida de las personas, por lo cual requiere para su cumplimiento, vincular no solo al Estado, sino también a los particulares que también están obligados con tales derechos, en virtud del principio de solidaridad .

4 Mónica Arbeláez-Rudas, Derecho a la salud en Colombia: el acceso a los servicios del Sistema General de Seguridad Social (Centro de Investigación y Educación Popular, CINEP, Bogotá, 2006).

5 Los derechos sociales están consagrados en el Título II Capítulo 2, sin que se consideren los únicos derechos previstos en la Constitución, ya que a lo largo de ella se pueden apreciar otras normas referentes a los derechos sociales (Preámbulo, artículo 1). Colombia, Constitución Política de 1991, versión corregida, 116 Gaceta Constitucional, 20 de julio de 1991. Disponible en: http://www. secretariasenado.gov.co/index.php/constitucion-politica

6 Beatriz González-Moreno, El Estado social. Naturaleza jurídica y estructura de los derechos sociales (Civitas Ediciones, Madrid, 2014).

7 Miguel Carbonell, Eficacia de la Constitución y derechos sociales: esbozo de algunos problemas, 6 Estudios Constitucionales, 2, 43-71 (2008). Disponible en: http://www.redalyc.org/articulo. oa? id=82060203

8 Víctor Abramovich \& Christian Courtis, Los derechos sociales como derechos exigibles (Trotta, Madrid, 2002).

9 La solidaridad constituye un principio fundante del Estado Social de Derecho, de allí que las autoridades de la República estén obligadas a asegurar el cumplimiento de los deberes sociales particulares previstos en el artículo 2 de la Constitución Política. Este principio se hace exigible ante situaciones estructurales de injusticia social, en las cuales la acción del Estado depende de 
Entre esos derechos, está la salud, cuya noción se desarrolla en la Constitución Política ${ }^{10}$ desde una doble connotación: como servicio público esencia ${ }^{11}$ — artículo 49-, como una actividad organizada $^{12}$, que les corresponde a las entidades prestadoras y debe realizarse en forma adecuada, oportuna, suficiente y continua por la correlativa necesidad de los usuarios de que no se les interrumpa de forma abrupta ni parcial este servicio ${ }^{13}$, es decir, que no puede ser suspendida por el peligro que puede generar para la vida, la seguridad o la salud de la población colombiana ${ }^{14}$. La prestación del servicio público de la salud está bajo la dirección y coordinación del Estado, que debe de manera responsable organizar, dirigir y reglamentar la prestación a todos los habitantes del territorio nacional, bajo la observancia de los principios de universalidad, eficiencia y solidaridad en los términos establecidos por la ley.

Y como derecho - artículos 44 y $48^{15}$ — de índole prestacional o de segunda generación, de la mano de la seguridad social que tiene

la contribución directa o indirecta de los asociados. Colombia, Corte Constitucional, Sentencia T-505-92, 28 de agosto de 1992, magistrado ponente Eduardo Cifuentes-Muñoz. Disponible en: http://www.corteconstitucional.gov.co/relatoria/1992/t-505-92.htm

10 Este derecho constitucional es el desarrollo del modelo político de Estado social europeo consolidado en la segunda mitad del siglo XX, resultado del nuevo constitucionalismo que reconoció los derechos sociales en el escenario del derecho internacional, a partir del cual Colombia ratificó importantes pactos y tratados de DESC. Diego Eduardo López-Medina, Sistema de salud y derecho a la salud. Historia de su interrelación en la jurisprudencia constitucional, artículo presentado en el congreso Contexto Económico y Jurisprudencial del Sistema de Salud, 25 de junio de 2008 (Bogotá, 2008).

11 En Colombia, los servicios públicos esenciales están ligados con el derecho a la huelga (artículo 56 $\mathrm{CP}$ ), en la medida que respecto de estos servicios existe la excepción a dicha garantía, es decir, que el derecho a la huelga no es absoluto y puede ser objeto de restricciones o prohibición. BERNARD Gernigon, Alberto Odero \& Horacio Guido, Principios de la OIT sobre el derecho a la huelga, 117 Revista Internacional del Trabajo, 4, 1-64, 37 (1998). Disponible en: https://www.fim-musicians. org/wp-content/uploads/right_to_strike_es.pdf)

12 "La determinación de si un servicio público es esencial debe tener en cuenta los siguientes factores: si contribuye de modo directo y concreto al respeto, vigencia, ejercicio y efectividad de los derechos y libertades fundamentales; si su interrupción puede ocasionar grave perjuicio a una parte de la población; si prevalecen los derechos garantizados mediante la prestación del servicio sobre el ejercicio del derecho de huelga en el caso concreto; y la situación política económica y social del Estado". Colombia, Corte Constitucional, Sentencia C-122-12, 22 de febrero de 2012, magistrado ponente Jorge Ignacio Pretelt-Chaljub. Disponible en: http:/www.corteconstitucional.gov.co/ relatoria/2012/C-122-12.htm

13 Colombia, Corte Constitucional, Sentencia SU-562-99, 4 de agosto de 1999, magistrado ponente Alejandro Martínez-Caballero. Disponible en: http://www.corteconstitucional.gov.co/relatoria/1999/ su562-99.htm

14 Organización Internacional del Trabajo, OIT, Libertad sindical y negociación colectiva - Estudio general de la Comisión de expertos en Aplicación de Convenios y Recomendaciones, Informe III (parte 4B) 69 Conferencia Internacional del Trabajo, CIT (OIT, Ginebra, 1983).

15 El artículo 48 de la Constitución Política dispone que la Seguridad Social es un servicio público obligatorio, cuya dirección, coordinación y control está a cargo del Estado, además advierte que este servicio público es esencial en lo relacionado con el Sistema General de Seguridad Social en 
un carácter obligatorio, que se presta bajo la dirección del Estado, de conformidad con los principios de eficiencia, universalidad y solidaridad. Aunque la Constitución Política no hace mención de manera expresa al término derecho a la salud, el artículo 44 recoge este concepto, al señalar que la salud es un derecho fundamental de los menores, derecho que es ampliado a la protección o seguridad social por parte del Estado — artículo 50-.

Durante su ejercicio, la Corte Constitucional ha reconocido la salud como un derecho fundamental, por medio de la acción de tutela y desde diferentes posturas:

1. La teoría de la fundamentalidad de los derechos por conexidad ${ }^{16}$, en virtud de la cual es viable proteger por vía de la acción de tutela ${ }^{17}$ un derecho social de la mano de un derecho fundamental - derecho a la vida, el derecho a la integridad personal y el derecho a la dignidad humana-, de tal suerte que se llega a considerar fundamental un derecho que en principio no lo es ${ }^{18}$.

2. Derecho de segunda generación o prestacional, en el cual el Estado está obligado a desarrollar acciones y dotar a la sociedad de una serie de bienes y servicios que aseguren la efectividad de ese derecho, frente al individuo, o en su defecto por los medios financieros de los particulares ${ }^{19}$.

3. Derecho fundamental con ocasión a los accionantes o sujetos de especial protección constitucional - menores de edad, adultos mayores, discapacitados, mujeres embarazadas, desplazados por la violencia, etc. ${ }^{20}$.

Salud (SGSSS).

16 Colombia, Corte Constitucional, Sentencia T-571-92, 26 de octubre de 1992, magistrado ponente Jaime Sanín-Greiffenstein. Disponible en: http://www.corteconstitucional.gov.co/relatoria/1992/t-571-92. htm

17 La sentencia T-406-92 hace una argumentación de la conexidad de los derechos que no aparecen como fundamentales: "Un derecho fundamental de aplicación inmediata que aparece como insuficiente para respaldar una decisión puede llegar a ser suficiente si se combina con un principio o con un derecho de tipo social o cultural y viceversa". Colombia, Corte Constitucional, Sentencia T-406-92, 5 de junio de 1992, magistrado ponente Ciro Angarita-Barón. Disponible en: http://www. corteconstitucional.gov.co/relatoria/1992/t-406-92.htm

18 Colombia, Corte Constitucional, Sentencia T-271-95, 23 de junio de 1995, magistrado ponente Alejandro Martínez-Caballero. Disponible en: http://www.corteconstitucional.gov.co/ relatoria/1995/t-271-95.htm

19 Robert Alexy, Teoría de los derechos fundamentales (Centro de Estudios Constitucionales, CEC, Madrid, 2007).

20 Colombia, Consejo de Estado, Sala de lo Contencioso Administrativo, Sección Quinta, Radicación 52001-23-33-000-2013-00377-01, 10 de abril de 2014, consejero ponente Alberto Yepes-Barreiro. Disponible en: https://docs.supersalud.gov.co/PortalWeb/Juridica/Sentencias/CE\%20SCA\%20 
4. Fundamentalidad del derecho a la salud, en atención a los servicios previstos en la Constitución y en la ley, como el Plan Obligatorio de Salud (POS), encaminados a garantizar la vida en condiciones de dignidad ${ }^{21}$.

La fundamentalidad de los derechos ${ }^{22}$ se reitera en las sentencias T-1081-01, T-760-08 y T-124-09²3, lo cual genera serias implicaciones al Estado, que debe comprometer financieramente su protección ${ }^{24}$. Por su parte, la Ley 100 de $1993^{25}$ implementó la política pública en salud y creó el Sistema General de Seguridad Social en Salud (SGSSS), que garantizaba a las personas hacer exigibles las prestaciones a las que el país se había comprometido ${ }^{26}$. En varios de sus artículos, esta ley desarrolló el concepto de salud como servicio público esencial, tal como lo advierte el artículo 154 que faculta al Estado para intervenir el servicio público de Seguridad Social en Salud, conforme a las reglas de competencia de que trata esta ley, en el marco de lo dispuesto en los artículos 48, 49, 334 y 365 a 370 de la Constitución Política, con el fin de garantizar la observancia de los principios consagrados en la Constitución. El artículo 156 establece que el Gobierno Nacional dirigirá, orientará, regulará, controlará y vigilará el servicio público esencial de salud que constituye el SGSSS.

SECV\%2052001-23-33-000-2013-00377-01(AC).pdf

21 Colombia, Corte Constitucional, Sentencia T-016-07, 22 de enero de 2007, magistrado ponente Humberto Antonio Sierra-Porto. Disponible en: http://www.corteconstitucional.gov.co/ relatoria/2007/t-016-07.htm

22 Para la Corte Constitucional, la fundamentalidad de los derechos no depende de la manera como estos se hacen efectivos, sino de su relación con la dignidad humana.

23 Colombia, Corte Constitucional, Sentencia T-1081-01, 11 de octubre de 2001, magistrado ponente Marco Gerardo Monroy-Cabra. Disponible en: http://www.corteconstitucional.gov.co/ relatoria/2001/t-1081-01.htm. Colombia, Corte Constitucional, Sentencia T-760-08, 31 de julio de 2008, magistrado ponente José Manuel Cepeda-Espinosa. Disponible en: http://www.corteconstitucional. gov.co/relatoria/2015/t-760-08.htm. Colombia, Corte Constitucional, Sentencia T-124-09, 24 de febrero de 2009, magistrado ponente Humberto Antonio Sierra-Porto. Disponible en: http://www. corteconstitucional.gov.co/relatoria/2009/t-124-09.htm

24 A partir de 2007 se da un desarrollo jurisprudencial respecto al uso de la acción de tutela para amparar de forma directa el derecho a la salud.

25 Colombia, Ley 100 de 1993, por la cual se crea el sistema de seguridad social integral y se dictan otras disposiciones, 41.148 Diario Oficial, 23 de diciembre de 1993. Disponible en: http://www. secretariasenado.gov.co/senado/basedoc/ley_0100_1993.html

26 Diego Eduardo López-Medina, Sistema de sălud y derecho a la salud. Historia de su interrelación en la jurisprudencia constitucional, artículo presentado en el congreso Contexto Económico y Jurisprudencial del Sistema de Salud, 25 de junio de 2008 (Bogotá, 2008). 
Así también, la Ley Estatutaria de Salud 1751 de $2015^{27}$ estableció la salud como un derecho fundamental ${ }^{28}$ autónomo e irrenunciable, individual y colectivo, que debe ser garantizado, regulado, bajo la construcción de formas o mecanismos de protección y velar por la integralidad y equidad en el acceso. Sin embargo, es importante advertir, que está ley solo establece una serie de principios a partir de los cuales debe establecerse el sistema de salud, razón por la cual se espera su reglamentación y posiblemente una nueva ley ordinaria que lo reorganice, reestructure y haga funcional. La sentencia C-313-14 moduló e hizo control previo y automático de legalidad de la ley ${ }^{29}$.

Entre los aspectos más relevantes de la ley están la eliminación de la diferenciación entre POS y No POS $^{30}$, que entró a operar en febrero de 2017, con lo cual se espera que solo haya un plan de beneficios que incluye todos los servicios, tecnologías y medicamentos, excepto los que estén en fase experimental, sean fuera del país y se puedan prestar en Colombia, no sean efectivos o sean meramente estéticos. También se eliminan los Comités Técnicos Científicos

27 Colombia, Ley Estatutaria 1751 de 2015, por medio de la cual se regula el derecho fundamental a la salud y se dictan otras disposiciones, 49.427 Diario Oficial, 16 de febrero de 2015. Disponible en: http://www.secretariasenado.gov.co/senado/basedoc/ley_1751_2015.html

28 Para algunos estudiosos de los temas de salud, el hecho de considerar la salud como un derecho fundamental dentro de la ley estatutaria constituye uno de los avances más importantes de los últimos años. Abrir la puerta al acceso a la salud sin trabas e impedimentos administrativos o financieros, constituye el reto más grande del sistema.

29 El argumento de la Corte sobre el derecho fundamental a la salud se basa en gran parte en la Observación General 14 del Pacto Internacional de Derechos Económicos, Sociales y Culturales (PIDESC) acerca de "el derecho al disfrute del más alto nivel posible de salud" (artículo 12), además: 1. Afirma que la sostenibilidad financiera del sistema no puede ser argumento para que el Estado niegue la prestación oportuna de los servicios... 3. Indica que no es posible interrumpir la garantía del derecho por razones administrativas o económicas. 4. Señala que no se puede sujetar la obligación de prestar el servicio a criterios de necesidad o eficiencia. 5. Manifiesta que ninguna entidad prestadora de atención en salud puede negar servicios en razón al estado terminal del usuario. 6. Aclara que cuando la norma se refiere a servicios y tecnologías debe entenderse como todos los elementos que pueden requerirse para prestar correctamente el servicio. 7. Indica que no puede requerirse ningún tipo de autorización administrativa cuando se trate de urgencias. 8. Las exclusiones del artículo 15 son taxativas y el gobierno no puede añadir más. 9. Finalmente, afirma que la regulación de precios de medicamentos es ajustada a la constitución. Mauricio Zagarra-CAyón \& Pablo Jaramillo, Actualización legal. La Corte Constitucional publicó la Sentencia C-313 de 2014 que verificó la constitucionalidad de la Ley Estatutaria de Salud (Norton Rose Fulbright, Bogotá, noviembre de 2014). Disponible en: http://www.nortonrosefulbright.com/files/la-corte-constitucional-publicola-sentencia-c-313-de-2014-que-verifico-la-constitucionalidad-de-la-ley-estatutaria-de-salud-pdf45kb-123085.pdf

30 Colombia, Ley Estatutaria 1751 de 2015, por medio de la cual se regula el derecho fundamental a la salud y se dictan otras disposiciones, 49.427 Diario Oficial, 16 de febrero de 2015. 
$(\mathrm{CTC})^{31}$, con lo que se espera permitir una mayor autonomía a los médicos en la toma de sus decisiones en los tratamientos de los pacientes pues en adelante serán los encargados de decidir la fórmula médica que los pacientes necesitan ${ }^{32}$. Otro de los aspectos relevantes es el hecho de facilitar el acceso a los servicios de salud y poner fin al llamado carrusel de la muerte ${ }^{33}$, pues la prestación de los servicios de urgencias sin autorización alguna es obligatoria.

A partir de la vigencia de la ley, se debe establecer como política pública el control a los precios $^{34}$ de los principios activos de medicamentos, razón por la cual los precios de los medicamentos controlados no pueden ser superiores al precio internacional de referencia —el gobierno debe determinar la metodología-.

\section{ANÁLISIS ECONÓMICO DE LAS DECISIONES DE TUTELA EN SALUD}

Una de las manifestaciones que aseguraron el cumplimiento de la prestación del servicio de salud está consagrada en los artículos 345 y 350 de la Carta Política, que se refieren a la ley de apropiaciones con el componente destinado al gasto público social — artículo 350 de la Constitución Política-, que debe satisfacer las necesidades básicas de la población, a partir de las asignaciones presupuestales. La materialización de estos requisitos se debe cumplir anualmente con la expedición de la ley anual del presupuesto nacional, de iniciativa gubernamental - Ministerio de Hacienda y Crédito Público - y expedida por el Congreso de la República ${ }^{35}$, dentro de la cual estaría contemplado el gasto social y el gasto público social.

31 Artículo 17 de la Ley Estatutaria 1751 de 2015.

32 El gremio de las Empresas Promotoras de Salud (EPS) se muestra muy preocupado por la financiación de estas nuevas medidas, pues representan mayores esfuerzos económicos y si no hay suficientes recursos se verán obligadas a negar el acceso al servicio. Ante esta problemática, el Ministerio de Salud considera que la sostenibilidad del sistema está garantizada con la nueva reforma tributaria que inyectará entre \$2,4 y \$2,5 billones más al presupuesto de la salud. Colombia, Ley 1819 de 2016, por medio de la cual se adopta una reforma tributaria estructural, se fortalecen los mecanismos para la lucha contra la evasión y la elusión fiscal, y se dictan otras disposiciones, 50.101 Diario Oficial, 29 de diciembre de 2016. Disponible en: http://www.secretariasenado.gov.co/senado/basedoc/ ley_1819_2016.html

33 Artículo 14 de la Ley Estatutaria 1751 de 2015.

34 Artículo 23 de la Ley Estatutaria 1751 de 2015.

35 La ley del presupuesto se expide conforme al Estatuto Orgánico del Presupuesto. Colombia, Decreto 111 de 1996, por el cual se compilan la Ley 38 de 1989, la Ley 179 de 1994 y la Ley 225 de 1995 que conforman el Estatuto Orgánico del Presupuesto, 42.692 Diario Oficial, 18 de enero de 1996. 
Durante los primeros años de vigencia de la Constitución Política, las apropiaciones presupuestales para el sector de la salud ${ }^{36}$ crecieron considerablemente año tras año.

Tabla 1

\begin{tabular}{|c|c|}
\hline Año & Apropiación presupuestal (pesos) \\
\hline 1992 & 413.117 .000 .000 \\
\hline 1993 & 568.204 .700 .000 \\
\hline 1994 & 869.849 .400 .000 \\
\hline 1995 & 1.493 .844 .700 .000 \\
\hline
\end{tabular}

Fuente: Luis Gonzalo Morales-SÁnchez, El financiamiento del sistema de seguridad social en salud en Colombia (LC/L.1037, Comisión Económica para América Latina y el Caribe, CEPAL, Santiago de Chile, 1997).

Este flujo de dinero resulta aún más significativo, cuando se analiza en términos relativos ${ }^{37}$, pues de acuerdo con la Comisión Económica para América Latina y el Caribe (CEPAL), la relación porcentual de la salud sobre el Producto Interno Bruto (PIB) tuvo dos aumentos importantes entre 1991 y 1992 de $0,20 \%$, con lo cual el gasto en la salud se ubicó en el 1,25\% sobre el PIB y entre 1994 y 1995 se incrementó en 1,61\% sobre el PIB, lo cual refleja un incremento del $0,18 \%$ frente a los años anteriores ${ }^{38}$.

Aunque el espíritu de la Ley 100 de 1993 era aliviar la responsabilidad del Estado en la prestación de la salud ${ }^{39}$, las cifras demuestran lo contrario ${ }^{40}$, pues a pesar del incremento en la asignación presupuestal para esos años, de acuerdo con el Informe presentado por la CEPAL, hay una correlación directa entre el aumento del gasto en salud y el giro de recursos al Instituto de Seguro Social

Disponible en: http://www.secretariasenado.gov.co/senado/basedoc/decreto_0111_1996.html

36 Luis Gonzalo Morales-SÁnchez, El financiamiento del sistema de seguridad social en salud en Colombia (LC/L.1037, Comisión Económica para América Latina y el Caribe, CEPAL, Santiago de Chile, 1997). Disponible en: http://archivo.cepal.org/pdfs/1997/S9700142.pdf

37 Luis Gonzalo Morales-SÁnchez, El financiamiento del sistema de seguridad social en salud en Colombia (LC/L.1037, Comisión Económica para América Latina y el Caribe, CEPAL, Santiago de Chile, 1997).

38 Luis Gonzalo Morales-SÁnchez, El financiamiento del sistema de seguridad social en salud en Colombia (LC/L.1037, Comisión Económica para América Latina y el Caribe, CEPAL, Santiago de Chile, 1997).

39 Consuelo Ahumada, Política social y reforma de salud en Colombia, 7 Papel Político, 9-35 (1998).

40 Luis Gonzalo Morales-SÁnchez, El financiamiento del sistema de seguridad social en salud en Colombia (LC/L.1037, Comisión Económica para América Latina y el Caribe, CEPAL, Santiago de Chile, 1997). 
(ISS) ${ }^{41}$, que pasó de manejar \$1.035.972 millones de pesos en 1992 a $\$ 2.797 .354$ millones de pesos en $1995^{42}$. Esto evidencia una gran variación en el comportamiento de estas cifras reportadas por el ISS, frente a las otras entidades que participaron del gasto público social por sectores en Colombia, como pensiones, educación, cultura y deporte, vivienda, agua, saneamiento ambiental, trabajo y gasto rural.

El aumento de las apropiaciones presupuestales en salud durante este período se atribuye a varias razones, entre ellas, la inflación legislativa y judicial ocurrida en esos años ${ }^{43}$, como consecuencia de la expedición de la Constitución Política de 1991 y la Ley 100 de 1993, que exigieron la regulación y reglamentación del SGSSS ${ }^{44}$.

A esta situación se le suma la aparición en escena de la acción de tutela, pues la determinación del derecho a la salud en la Constitución Política y en la ley no fue suficiente para tener un amparo efectivo, razón por la cual se requirió un juez especializado que resolviera las acciones de tutela al respecto ${ }^{45}$. Mediante las primeras decisiones de la Corte Constitucional ${ }^{46}$, se buscó amparar el

41 Colombia, Ley 90 de 1946, por la cual se establece el seguro social obligatorio y se crea el Instituto Colombiano de Seguros Sociales, 23.112 Diario Oficial, 7 de enero de 1947. Disponible en: http:// www.suin-juriscol.gov.co/viewDocument.asp?id=1631247. El Instituto de Seguros Sociales, entidad creada en 1946, se encargó por más de cincuenta años de la seguridad social de la gran mayoría de los colombianos. Mateo Montes, Historial Pensiones Instituto de Seguros Sociales (ISS) (16 de julio de 2015). Disponible en: http://www.colconectada.com/historial-pensiones-instituto-deseguros-sociales-iss/. Hoy, la Nueva EPS administra la salud y Colpensiones, las pensiones.

42 Luis Gonzalo Morales-Sánchez, El financiamiento del sistema de seguridad social en salud en Colombia (LC/L.1037, Comisión Económica para América Latina y el Caribe, CEPAL, Santiago de Chile, 1997).

43 Sergio Clavijo, Fallos y fallas económicas de las altas cortes: el caso de Colombia 1991-2000, 173 Borradores de Economía, 1-42 (2001). Disponible en: http://www.banrep.gov.co/docum/ftp/ borra173.pdf

44 Sergio Clavijo, Fallos y fallas económicas de las altas cortes: el caso de Colombia 1991-2000, 173 Borradores de Economía, 1-42 (2001).

45 Óscar Dueñas-Ruiz, Acción y procedimiento en la tutela (Librería del Profesional, Bogotá, 2009).

46 Entre otras sentencias, Colombia, Corte Constitucional, Sentencia T-484-92, 11 de agosto de 1992, magistrados ponentes Simón Rodríguez-Rodríguez, Jaime Sanín-Greiffenstein. Disponible en: http://www.corteconstitucional.gov.co/relatoria/1992/t-484-92.htm. Colombia, Corte Constitucional, Sentencia T-522-92, 19 de septiembre de 1992, magistrado ponente Alejandro Martínez-Caballero. Disponible en: http://www.corteconstitucional.gov.co/relatoria/1992/t-522-92.htm. Colombia, Corte Constitucional, Sentencia T-116-93, 26 de marzo de 1993, magistrado ponente Hernando Herrera-Vergara. Disponible en: http://www.corteconstitucional.gov.co/relatoria/1993/t-116-93.htm. Colombia, Corte Constitucional, Sentencia T-388-93, 15 de septiembre de 1993, magistrado ponente Hernando Herrera-Vergara. Disponible en: http://www.corteconstitucional.gov.co/relatoria/1993/t-388-93. htm. Colombia, Corte Constitucional, Sentencia T-030-94, 2 de febrero de 1994, magistrado ponente Alejandro Martínez Caballero. Disponible en: http://www.corteconstitucional. gov.co/relatoria/1994/t-030-94.htm. Colombia, Corte Constitucional, Sentencia T-192-94, 20 de abril de 1994, magistrado ponente José Gregorio Hernández-Galindo. Disponible en: http://www. 
derecho a la salud ${ }^{47}$ de miles de ciudadanos, contra la negación de servicios y la restricción al sistema de salud ${ }^{48}$, muchas de ellas bajo el argumento de que la salud es un derecho social que implica obligaciones progresivas y que puede ser justiciable, por lo cual resulta completamente exigible ante el juez constitucional ${ }^{49}$.

\section{A. Acción de tutela y Plan Obligatorio de Salud (POS)}

El uso de la acción de tutela - que a continuación se refiere - corresponde a un período comprendido entre 1991, fecha de entrada en vigencia de la Constitución Política, y 2015, año en el cual se sancionó la Ley Estatutaria de Salud 1751, que abre la puerta al desarrollo de medidas encaminadas a garantizar el derecho fundamental a la salud a todos los colombianos y al progreso del SGSSS. Aunque el propósito de la ley genera una gran expectativa, respecto de lo que será el manejo del POS a partir de la eliminación de su diferenciación, en cuanto al uso de la acción de tutela, sin mayor esfuerzo, se puede inferir que el número de acciones interpuestas para garantizar el derecho a la salud no tendrá mayor reducción a corto plazo, ya que el porcentaje más alto de amparos solicitados son por prestaciones incluidas en el POS y no, como se creería, por solicitudes No POS.

La Corte Constitucional ha asumido una posición garantista frente al derecho fundamental de la salud; la mayoría de las acciones de tutela interpuestas en los últimos años se relaciona con servicios garantizados en el Plan Obligatorio de Salud (POS), que fueron

corteconstitucional.gov.co/relatoria/1994/t-192-94.htm. Colombia, Corte Constitucional, Sentencia T-271-95, 23 de junio de 1995, magistrado ponente Alejandro Martínez-Caballero. Disponible en: http://www.corteconstitucional.gov.co/relatoria/1995/t-271-95.htm. Colombia, Corte Constitucional, Sentencia T-383-95, 31 de agosto de 1995, magistrado ponente Alejandro Martínez-Caballero. Disponible en: http://www.corteconstitucional.gov.co/relatoria/1995/t-383-95.htm

47 De forma reiterada, la Corte Constitucional insistió en la necesidad de proteger el derecho a la salud, por tratarse de un derecho irrenunciable, universal, inspirado en los principios constitucionales del Estado social de derecho, solidaridad y dignidad humana, que persiguen el cumplimiento material y efectivo de las garantías constitucionales.

48 Jorge Humberto Blanco-Restrepo \& José María Maya-Mejía, Fundamentos de salud pública (Corporación para Investigaciones Biológicas, CIB, Medellín, 2005).

49 Víctor Abramovich \& Christian Courtis, Hacia la exigibilidad de los derechos económicos, sociales y culturales: estándares internacionales y criterios de aplicación ante los tribunales locales, en $L a$ aplicación de los tratados sobre derechos humanos por los tribunales locales, 283-350 (MARTíN Abregú, comp., Editores del Puerto, Buenos Aires, 1997). 
negados por las EPS elegidas por los usuarios para afiliarse, para que estas administren sus cotizaciones y autoricen las prestaciones médicas. Las cifras recolectadas desde 2003 hasta 2015, sobre tutelas por servicios POS, revelan constantes barreras al acceso que sufren los usuarios del SGSSS, que en teoría no deberían existir, debido a que esas prestaciones ya han sido cubiertas desde la afiliación y cotización de las personas, con la Unidad de Pago por Capitación $(\mathrm{UPC})^{50}$, que es el valor del POS para los afiliados ${ }^{51}$.

A pesar de que los planes obligatorios de salud (POS) del régimen contributivo y subsidiado se unificaron en cumplimiento de la Ley 100 de 1993 y la sentencia T-760-08, a partir del 1 de julio de 2012, con el fin de que los afiliados pudieran acceder a los mismos servicios de salud ${ }^{52}$, del incremento en los recursos del sector salud, que pasó de una asignación presupuestal de \$2.112 miles de millones de pesos en 1996 a $\$ 20.869$ miles de millones para $2016^{53}$ y $\$ 22.017$ miles de millones para $2017^{54}$, que el país está en proceso de tener una cobertura total, el número de tutelas para reclamar servicios de salud por el POS se incrementó, lo cual da continuidad al problema de inequidad de la salud, además de la violación de los principios constitucionales de eficiencia, universalidad y solidaridad. Del total

50 "La Unidad de Pago por Capitación (UPC) es el valor per cápita que reconoce el Sistema General de Seguridad Social en Salud a cada EPS por la organización y garantía de la prestación de los servicios de salud contenidos en el Plan Obligatorio de Salud, sin distinción o segmentación alguna por niveles de complejidad o tecnologías específicas. La UPC tiene en cuenta los factores de ajuste por género, edad y zona geográfica, para cubrir los riesgos de ocurrencia de enfermedades que resulten en demanda de servicios de los afiliados a cualquiera de los regímenes vigentes en el país". Conozca qué es la unidad de pago por capitación. Disponible en: http://goo.gl/9Hpzht

51 Colombia, Defensoría del Pueblo, La tutela y los derechos a la salud y a la seguridad social, 2014 (Defensoría del Pueblo, Bogotá, 2015).

52 Durante su gestión (2007-2012), la Comisión de Regulación en Salud, CRES, expidió cuatro Acuerdos relacionados con la Unificación: Acuerdo 04 de 2009 que unificó el POS para los niños de 0 a 12 años; Acuerdo 011 de 2010 que unificó el POS para los niños y adolescentes menores de 18 años; Acuerdo 027 de 2011 que unificó el POS para los adultos de 60 y más años; Acuerdo 032 de 2012 que unificó el POS para los adultos entre 18 y 59 años. Ministerio de Salud y Protección Social, ABC de la unificación del POS (Boletín de Prensa 186 de 2012, 16 de julio de 2012). Disponible en: https://www.minsalud.gov.co/Paginas/ABC\%20de\%20la\%20Unificaci\%C3\%B3n\%20del\%20POS. aspx

53 Ministerio de Hacienda, Boletín 110 (Bogotá, 2015). Disponible en línea: http://www.minhacienda. gov.co/HomeMinhacienda/ShowProperty;jsessionid=xQsphY0tWC-QOGzurHsKcsY23kNkoDl7Eg X1iMvUmNsM613OcQJ5!508618735?nodeId=\%2FOCS\%2FMIG_41322604.PDF\%2F\%2FidcPrim aryFile\&revision=latestreleased

54 La ley 1769 del 24 de noviembre de 2015 aprobó el Presupuesto General de la Nación para el año 2016 de \$215,9 billones de pesos. La ley 1815 de 2016 aprobó el Presupuesto General de la Nación para el año 2017 de \$224,4 billones de pesos. Ministerio de Hacienda, Boletín 176 (Bogotá, 2016). Disponible en línea: http://www.minhacienda.gov.co/HomeMinhacienda/ShowProperty?nodeId=/ OCS/P_MHCP_WCC-059064//idcPrimaryFile\&revision=latestreleased 
de tutelas analizadas por la Defensoría del Pueblo, en su estudio sobre el derecho a la Salud, se evidencia con preocupación, el elevado porcentaje de acciones interpuestas para hacer valer el POS, que para el año 2015 fue de $64,08 \%{ }^{55}$, cuyo porcentaje más alto se ubicó en el régimen subsidiado ${ }^{56}$, en comparación con el régimen contributivo; luego el régimen subsidiado parece enfrentar mayores obstáculos en el acceso a las prestaciones, lo cual consolida un mayor problema de inequidad en la estructura de salud, pues en este régimen están los usuarios de más bajos recursos ${ }^{57}$.

En ese orden de ideas, el desarrollo jurisprudencial frente a tutelas que solicitan servicios y medicamentos incluidos en el POS, ha estado encaminado a destacar que el derecho a la salud se materializa como un derecho subjetivo en cabeza de todos los beneficiarios del SGSSS ${ }^{58}$, pues no hay lugar a rechazos o demoras cuando las prestaciones están efectivamente cubiertas. Sobre el particular, la Corte Constitucional se pronunció en 2011 y reiteró que la real prestación de bienes y servicios cubiertos en el POS está enmarcada dentro del mandato del artículo 48 de la Constitución Política, al indicar que el Estado debe regular el sistema de salud, especialmente, para el goce efectivo de su respectivo derecho ${ }^{59}$. Bajo los mismos postulados, las decisiones de tutela T-736-04 y T-922-0960, entre otras, han convergido a señalar que la viabilidad de la tutela en cuanto a solicitud de procedimientos o medicamentos incluidos en el POS debe cumplir tres requisitos: i) Que la prestación haya

55 Colombia, Defensoría del Pueblo. La tutela y los derechos a la salud y a la seguridad social, 2015 (Defensoría del Pueblo, Bogotá, 2016).

56 Por citar un ejemplo, en 2014 las solicitudes por servicios POS son de 65,74\% y las del régimen subsidiado superaron en 9 puntos porcentuales al régimen contributivo. Colombia, Defensoría del Pueblo. La tutela y los derechos a la salud y a la seguridad social, 2015 (Defensoría del Pueblo, Bogotá, 2016).

57 IsABel Eugenia BelalcÁzAR-PEÑa, La equidad en el plan obligatorio de salud colombiano: una visión comparada (Tesis de maestría, Universidad Nacional de Colombia, Bogotá, 2013). Disponible en: http://www.bdigital.unal.edu.co/9019/1/isabeleugeniabelalcazarpe\%C3\%B1a.2012.pdf

58 Colombia, Defensoría del Pueblo. La tutela y los derechos a la salud y a la seguridad social, 2015 (Defensoría del Pueblo, Bogotá, 2016).

59 Colombia, Corte Constitucional, Sentencia T-320-11, 4 de mayo de 2011, magistrado ponente Jorge Iván Palacio-Palacio. Disponible en: http://www.corteconstitucional.gov.co/relatoria/2011/t-320-11. htm

60 Colombia, Corte Constitucional, Sentencia T-736-04, 5 de agosto de 2004, magistrado ponente Clara Inés Vargas-Hernández. Disponible en: http:/www.corteconstitucional.gov.co/ relatoria/2004/t-736-04.htm. Colombia, Corte Constitucional, Sentencia T-922-09, 9 de diciembre de 2009, magistrado ponente Jorge Iván Palacio-Palacio. Disponible en: http://www.corteconstitucional. gov.co/relatoria/2009/t-922-09.htm 
sido ordenada por un médico adscrito a la entidad de salud; ii) Que sea necesaria para la conservación de un derecho fundamental; iii) Que ya se haya solicitado a la entidad encargada de la prestación ${ }^{61}$. Muchas de las acciones de tutela relacionadas con el POS obedecen principalmente a los altos precios de medicamentos, que impiden a las personas acceder a ellos. La inelasticidad de los precios ha sido explotada por los laboratorios farmacéuticos, que cobran por estos bienes un precio mayor sin que haya riesgo de reducción en el número de pacientes que asisten, gracias a que el Fondo de Seguridad y Garantía (Fosyga) actúa como una "chequera ciega" que refuerza esta problemática ${ }^{62}$. La Ley 100 de 1993, artículo 245, creó la Comisión Nacional de Precios de Medicamentos, a pesar de que ha habido regulación respecto de la metodología del control de precios y de los intentos por regular de precios en medicamentos y dispositivos médicos, han sido esfuerzos tardíos e insuficientes dentro de un contexto en el cual la columna vertebral de la competencia - que es la oferta y la demanda - no funciona con las farmacéuticas, que en lugar de luchar por reducir los costos en beneficio de los consumidores, se ha aumentado descomunalmen$t^{63}$, como consecuencia de la política de liberalización de precios emprendida por el Estado colombiano a partir de la Circular $04 \mathrm{de}$ $2006^{64}$ — desregulación total de los precios de los medicamentosque llevó a que los laboratorios no tuvieran límites marco que les impidieran cobrar lo que ellos a bien tuvieran como conveniente. La desregulación de los precios de los medicamentos se considera

61 Colombia, Corte Constitucional, Sentencia T-922-09, 9 de diciembre de 2009, magistrado ponente Jorge Iván Palacio-Palacio.

62 David Bardey, Los precios de los medicamentos en Colombia, Blogoeconomia (27 de mayo de 2013). Disponible en: http://lasillavacia.com/elblogueo/blog/los-precios-de-los-medicamentos-encolombia-por-david-bardey, https://goo.gl/C1YrGX

63 Para ejemplificar, Óscar Andia, vicepresidente de asuntos farmacéuticos de la Federación Médica Colombiana, manifestó que el medicamento NovoSeven — usado por los hemofílicos - tiene un precio promedio en 21 países de 2,5 millones de pesos (US\$833) y en Colombia llegó a costar 14 millones de pesos (US\$4.666). Luis FaJARDo, ¿Por qué Colombia paga los medicamentos más caros de América Latina?, BBC Mundo (10 de marzo de 2015). Disponible en: http://www.bbc.com/mundo/ noticias/2015/03/150220 economia medicamentos colombia lf?ocid=socialflow twitter, https:// goo.gl/DzumpE. Tasa de cambio promedio de referencia: 3.000 pesos colombianos por dólar (COP/ US\$).

64 Con esta Circular se estableció la libertad vigilada para todos los medicamentos comercializados en el país y derogó el régimen de control directo universal y automático de los precios de medicamentos. Colombia, Comisión Nacional de Precios de Medicamentos, CNPM, Circular 04 de 2006, 1 de septiembre de 2006. Disponible en: http://www.sic.gov.co/sites/default/files/files/circular4_2006. pdf 
como uno de los casos más aberrantes de corrupción en el país, que debilitó al Estado, su credibilidad institucionalidad y su legitimidad, como señala la Federación Médica Colombiana:

(...) Colombia se convirtió en un caso mundial de inmoralidad administrativa, con evidente favorecimiento a las farmacéuticas, daño patrimonial del Estado y omisión grave por parte de los funcionarios públicos de su obligación legal de defender los intereses de la salud pública ${ }^{65}$.

El artículo 23 de la Ley Estatutaria de Salud 1751 de 2015 estableció que la regulación de precios debe estar a cargo del gobierno nacional. El artículo 72 de la Ley 1753 de $2015^{66}$ creó la Comisión Nacional de Precios de Medicamentos y Dispositivos ${ }^{67}$, a la que le atribuyó la facultad de diseñar la metodología y los mecanismos de regulación de precios de medicamentos, previa delegación del gobierno nacional. En virtud de la normativa anterior, se profirió el Decreto 705 de $2016^{68}$, que delegó a la Comisión Nacional de Precios de Medicamentos y Dispositivos Médicos la definición de la metodología y los mecanismos para la regulación de precios de medicamentos, así como la regulación de los márgenes de distribución y comercialización de los mismos, que desde 2016 está a cargo de regular e incrementar los precios de los medicamentos.

Ahora bien, la otra cara de las reclamaciones vía tutela por No POS, que refleja el vacío de regulación y gestión de servicios excluidos de la cobertura, ha sido el espacio que los jueces de tutela han ocupado como ordenadores del gasto en salud y gestores de los servicios que las EPS en principio no están obligadas a prestar, pero que al final deben atender. Aunque las providencias de

65 Humberto de la Calle, Jorge Enrique Robledo, Claudia Morales, Armando Estrada-Villa, Oscar Andia, Norbey Quevedo-Hernández, Joan Avellaneda-Silva, Beatriz Sánchez-Herrera, Wilson Arias \& Jorge Iván GonzÁlez, Perlas de la corrupción (Debate, Bogotá, 2013).

66 Colombia, Ley 1753 de 2015, por la cual se expide el Plan Nacional de Desarrollo 2014-2018 “Todos por un nuevo país", 49.538 Diario Oficial, 9 de junio de 2015. Disponible en: http://www.secretaria senado.gov.co/senado/basedoc/ley_1753_2015.html

67 “'La creación de esta comisión es muy importante ya que garantiza que haya un equilibrio en la toma de decisiones respecto a la fijación de la política de estos precios. Así, se tendrá en cuenta al consumidor final y a las empresas fabricantes de los mismos', aseguró el viceministro de Desarrollo Empresarial, Daniel Arango Ángel”. Economía, Lista comisión que fijará precios de medicamentos, El Tiempo (2 de mayo de 2016). Disponible en: http://www.eltiempo.com/archivo/documento/CMS16579583

68 Colombia, Decreto 705 de 2016, por el cual se establecen disposiciones sobre el proceso de regulación de precios de medicamentos a nivel nacional, 49.857 Diario Oficial, 27 de abril de 2016. Disponible en: http://www.suin-juriscol.gov.co/viewDocument.asp?id=30020258 
tutela por parte de la Corte Constitucional están encaminadas a lograr la optimización social ${ }^{69}$, han tenido un impacto económico muy discutido desde la entrada en vigor de la Ley 100 de 1993. El desarrollo jurisprudencial evidencia que, por medio de revisiones de tutela que solicitan prestaciones fuera del POS, hay situaciones que ameritan la prestación, a pesar de la falta de cobertura y de que son las Entidades Promotoras de Salud (EPS) las encargadas de hacerlas efectivas, para luego repetir al Fosyga ${ }^{70}$.

La Corte Constitucional ha previsto en los casos en que se soliciten tratamientos o medicamentos fuera del POS, que el juez constitucional está en el deber de revisar los siguientes requisitos: 1) Que esta exclusión amenace los derechos fundamentales del paciente; 2) que el medicamento o servicio no pueda ser sustituido por un bien que esté en el POS - o que al sustituirlo, disminuya su efectividad-; 3) el servicio o medicamento fue ordenado por un médico de la entidad de salud correspondiente; 4) y el paciente no tiene la capacidad para costearlo ${ }^{71}$.

En cuanto al número de tutelas interpuestas durante la vigencia de la Ley Estatutaria de Salud 1751 de 2015, no ha habido un cambio considerable, pues la tutela sigue siendo el mecanismo más utilizado para garantizar el derecho a la salud.

\section{B. Acciones de tutela y enfermedades de alto costo}

La prestación del derecho a la salud implica atender las diferentes necesidades de sus afiliados, pues genera una carga económica distinta frente a las finanzas del sector salud que soportan el SGSSS. Algunos afiliados pueden pasar infinidad de años sin requerir siquiera una consulta médica o un medicamento, pero otros, por el contrario, pueden demandar atención médica de alta complejidad y por tanto, requerir gran parte de los recursos invertidos en la salud ${ }^{72}$.

69 Sergio Clavijo, Fallos y fallas económicas de las altas cortes: el caso de Colombia 1991-2000, 173 Borradores de Economía, 1-42 (2001).

70 Colombia, Corte Constitucional, Sentencia T-320-11, 4 de mayo de 2011, magistrado ponente Jorge Iván Palacio-Palacio.

71 Colombia, Corte Constitucional, Sentencia T-017-13, 25 de enero de 2013, magistrado ponente Luis Ernesto Vargas-Silva. Disponible en: http://www.corteconstitucional.gov.co/relatoria/2013/t-017-13. htm

72 Inés Milena David, Ana María Medina \& Elkin Martínez, Enfermedades de alto costo en afiliados a un sistema institucional de aseguramiento y prestación de servicios de salud, 24 Revista Facultad 
A este último grupo pertenecen los pacientes con enfermedades de alto $\operatorname{costo}^{73}$, considerados por la Corte Constitucional como sujetos de especial protección constitucional. El Sistema de salud debe tener identificados los criterios de las patologías que corresponden a la categoría de enfermedades de alto $\operatorname{costo}^{74}$, para poder garantizar el acceso y la prestación eficiente de los servicios de salud.

El primer criterio se basa en que la población no presenta un riesgo homogéneo y por tanto, hay subgrupos que, por su estado de salud, tienen mayor probabilidad de consumir servicios. Por esto, en términos generales, de toda la población existente entre $20 \mathrm{y}$ $30 \%$ consume el $70 \%$ de los recursos gastados, mientras el resto solo requiere servicios que representan el 30\% del gasto ${ }^{75}$. Identificar a los individuos de alto costo permite garantizar los recursos para el gasto futuro probable por servicios de salud, al determinar primas de aseguramiento diferenciales, asignación diferencial de recursos, o mecanismos de compensación.

El segundo criterio se encamina a la posibilidad de gestionar e intervenir la enfermedad y los desenlaces evitables, si se identifica a los pacientes de mayor riesgo ${ }^{76}$. El tercer criterio se refiere a que para identificar patologías de alto costo, se debe proteger a los pacientes afectados, sus familias y a la sociedad en general contra el riesgo de catástrofe financiera ${ }^{77}$, pues los costos de estas patologías son muy elevados y los porcentajes que deben cubrir los usuarios, por pequeños que sean, pueden afectar notoriamente su economía.

Nacional de Salud Pública, 2, 98-104 (2006). Disponible en: https://aprendeenlinea.udea.edu.co/ revistas/index.php/fnsp/article/view/249/178

73 Las enfermedades de alto costo se consideran ruinosas o catastróficas, de alta complejidad técnica en su manejo, alto costo financiero y baja ocurrencia y costo de efectividad en su tratamiento. En esta consideración están los pacientes terminales o con enfermedades crónicas que requieren tratamientos prolongados con medicamentos.

74 Colombia, Ministerio de Salud, Criterios para identificar patologías de alto costo en Colombia (Bogotá, 2014). Disponible en: https://www.minsalud.gov.co/sites/rid/Lists/BibliotecaDigital/RIDE/ INEC/CAC/ALTO_COSTO_FINAL_070911.pdf

75 Colombia, Ministerio de Salud, Criterios para identificar patologías de alto costo en Colombia (Bogotá, 2014).

76 Se les ofrece intervenciones de prevención secundaria y terciaria y gerenciar de manera especial su riesgo y su enfermedad para modificar la ruta de atención y resultados de estos pacientes, dado que presentan un riesgo incrementado de complicaciones, muerte y consumo de recursos, superior a los de la población general. Colombia, Ministerio de Salud, Criterios para identificar patologías de alto costo en Colombia (Bogotá, 2014).

77 Colombia, Ministerio de Salud, Criterios para identificar patologías de alto costo en Colombia (Bogotá, 2014). 
Las tres enfermedades catastróficas que más costos generan al sistema son las cardiovasculares, las neoplasias (cáncer) y la insuficiencia renal. De los costos totales, el 65\% corresponde a enfermedades catastróficas y el 30\% se ha gastado en pacientes que fallecieron durante el tratamiento ${ }^{78}$. Para la Asociación Colombiana de Empresas de Medicina Integral (ACEMI), en su publicación Cifras e indicadores del Sistema de Salud (2015), los servicios de alto costo en el país ${ }^{79}$ son la hospitalización en unidad de cuidados intensivos (UCI) neonatal, pediátrica y adulto; la quimioterapia; la atención a pacientes quemados; las diálisis y los servicios quirúrgicos.

A modo de ejemplo y para dimensionar el valor de las enfermedades de alto costo, los pacientes con fibrosis quística requieren 17 medicamentos, 10 de los cuales no están en el POS y según un estudio realizado por la Fundación Colombiana para Fibrosis Quística, el costo de un paciente controlado es de \$30 millones mensuales; pero en el evento de no estar controlado, una sola hospitalización le puede costar al sistema $\$ 2.000$ millones de pesos $^{80}$. Enfermedades como la hipertensión requieren elevados costos derivados de medicamentos y remisiones: la hipertensión arterial pulmonar, por ejemplo, puede costar entre US\$30.000 a US\$90.000 por paciente y por año dependiendo de la complejidad ${ }^{81}$; la diabetes relaciona su importe a procedimientos diagnósticos, en especial de laboratorio, tanto para la confirmación de la presencia de la enfermedad como para atender las múltiples complicaciones macro y microvasculares que ella genera. Para 2013, la diabetes generó un gasto sanitario que superó los US\$548.000 millones de dólares, un 11\% del presupuesto en salud del planeta ${ }^{82}$; las hemodiálisis en los pacientes que

78 Karina Gallardo-Solarte, Fanny Patricia Benavides-Acosta \& Rosario Rosales-Jiménez, Costos de la enfermedad crónica no transmisible: la realidad colombiana, 14 Revista Ciencias de la Salud, 1, 103-114 (2016). Disponible en: http://revistas.urosario.edu.co/index.php/revsalud/article/view/4596

79 Asociación Colombiana de Empresas de Medicina Integral, ACEMI, Cifras e indicadores del Sistema de Salud-2015 (Asociación Colombiana de Empresas de Medicina Integral, ACEMI, Bogotá, 2015). Disponible en: https://acemi.org.co/index.php/acemi-defecto/9-actualidad/620-cifras-e-indicadoresdel-sistema-de-salud-publicacion-2015

80 El viacrucis del paciente de alto costo, Revista Semana (Tratamiento, 13 de febrero de 2016). Disponible en: https://goo.gl/zTsiwU

81 Manuel Benavides-Luna, Adriana Torres-Navas \& Carlos Arias-Barrera, Aspectos sobre tratamiento, detección y costos en el enfoque de la hipertensión arterial pulmonar, 25 Revista Colombiana de Neumología, 3, 133-135 (2013). Disponible en: http://revistas.asoneumocito.org/ index.php/rcneumologia/article/viewFile/104/100

82 El costo que tiene la diabetes, Portafolio (Tendencias, 2 de octubre de 2016). Disponible en: http:// www.portafolio.co/tendencias/costo-diabetes-50680 
han desarrollado una nefropatía irreversible implican valores muy altos, dadas la complejidad del procedimiento, la frecuencia con la cual hay que realizarlo -3 veces por semana $-\mathrm{y}$ su indicación de perpetuidad ${ }^{83}$.

El cáncer es otra de las patologías que reportan elevados gastos, dependiendo de la etapa en que esté. Por ejemplo, en el cáncer de mama los estadios más cuantiosos por persona, son el regional con un costo total de $\$ 65.603 .537$ y el cáncer metastásico, con un costo total de $\$ 144.400 .865^{84}$.

Los costos de la diabetes en un paciente con patología tipo 2, fueron estimados para el año 2008, en indirectos US\$559, directos US\$288 y costo total US\$847. Se estima, además, que el tratamiento de las complicaciones macrovasculares constituye el 86\% de los costos directos anuales y el 95\% de los costos indirectos de un paciente con diabetes tipo 2. El valor promedio de los servicios médicos ocasionados por un paciente cardiovascular es de $\$ 12,8$ millones de pesos y multiplicado por todos los usuarios con este tipo de patologías es de $\$ 13,2$ billones de pesos en el período comprendido entre 2002 y 2007, según un estudio realizado por el Ministerio de Protección Social y la Universidad de Antioquia. En el caso de la artritis reumatoide, los costos de la terapia biológica para el tratamiento de esta patología representan para el Estado colombiano unos $\$ 20.000$ millones de pesos anuales, pues los costos de esa enfermedad, si bien son inferiores a los trasplantes de corazón o medula ósea, son superiores a la mayoría de los que generan otras enfermedades consideradas de alto costo, ruinosas o catastróficas. En promedio, la atención de la enfermedad leve, moderada y grave cuesta US\$1.689, US\$1.805 y US\$23.441, respectivamente ${ }^{85}$.

La Universidad de Antioquia analizó los registros y facturas por enfermedades de alta complejidad técnica en la población afi-

83 Karina Gallardo-Solarte, Fanny Patricia Benavides-Acosta \& Rosario Rosales-Jiménez, Costos de la enfermedad crónica no transmisible: la realidad colombiana, 14 Revista Ciencias de la Salud, 1, 103-114 (2016).

84 Óscar Gamboa, Lina Angélica Buitrago, Teófilo lozano, Sabrina Dieleman, Carlos Gamboa, Érika León-Guzmán, Milena Gila \& Juan Fuentes, Costos directos de la atención del cáncer de mama en Colombia, 20 Revista Colombiana de Cancerología, 2, 52-60 (2016). Disponible en: http:// www.elsevier.es/es-revista-revista-colombiana-cancerologia-361-articulo-costos-directos-atenciondel-cancer-S0123901516300014

85 Karina Gallardo-Solarte, Fanny Patricia Benavides-Acosta \& Rosario Rosales-Jiménez, Costos de la enfermedad crónica no transmisible: la realidad colombiana, 14 Revista Ciencias de la Salud, 1, 103-114 (2016). 
liada - cotizantes y beneficiarios - de la entidad aseguradora y asistencial - IPS Universitaria - de la misma universidad, durante un período de 5 años (1999-2003) ${ }^{86}$. Este estudio concluyó que durante ese lapso se presentaron 245 casos de Enfermedades de Alto Costo (EAC), lo cual representa un promedio de 49 casos por año y una tasa de 5 casos de alto costo por cada 1.000 afiliados e identificó que las tres enfermedades que generan el más alto costo son las cardiovasculares, las neoplasias y la insuficiencia renal. Estas representan $65 \%$ de los costos totales durante el período estudiado ${ }^{87}$.

La forma como se abordan estas patologías en Colombia ha evolucionado y va más allá de la protección financiera de los ciudadanos, la cual se ha buscado por medio de la cobertura universal - mayor del 95\% - y con niveles de pagos de bolsillo por debajo del 5\%. Para neutralizar el efecto de la selección de riesgos entre aseguradoras y desincentivar la selección o discriminación de los pacientes con patologías de alto costo, se incorporó al sistema un ajuste de riesgo, con base en un mecanismo de redistribución de recursos entre todas las aseguradoras de salud, el fondo de compensación Cuenta de Alto Costo (CAC) del Fondo Colombiano de Enfermedades de Alto Costo ${ }^{88}$.

86 Inés Milena David, Ana María Medina \& Elkin Martínez, Enfermedades de alto costo en afiliados a un sistema institucional de aseguramiento y prestación de servicios de salud, 24 Revista Facultad Nacional de Salud Pública, 2, 98-104 (2006).

87 Inés Milena David, Ana María Medina \& Elkin Martínez, Enfermedades de alto costo en afiliados a un sistema institucional de aseguramiento y prestación de servicios de salud, 24 Revista Facultad Nacional de Salud Pública, 2, 98-104 (2006).

88 El Decreto 2699 de 2007 creó la Cuenta de Alto Costo y dijo que le corresponde al Ministerio de la Protección Social determinar las enfermedades ruinosas y catastróficas (alto costo). Colombia, Decreto 2699 de 2007, por el cual se establecen algunas normas relacionadas con el Sistema General del Seguridad Social en Salud y se dictan otras disposiciones, 46.688 Diario Oficial, 13 de julio de 2007. Disponible en: http://www.suin-juriscol.gov.co/viewDocument.asp?id=1482079. La resolución 3974 de 2009 considera conveniente atender criterios de selección y priorización. La Resolución 2565 de 2007 y la resolución 3974 de 2009 establecen con fines de ajuste por la Cuenta de Alto Costo, una lista de patologías consideradas de alto costo a saber: enfermedad renal crónica; cáncer de cérvix; cáncer de mama; cáncer de estómago; cáncer de colon y recto; cáncer de próstata; leucemia linfoide aguda; leucemia mieloide aguda; linfoma Hodgkin; linfoma no Hodgkin; epilepsia; artritis reumatoide; VIH/SIDA. Colombia, Ministerio de la Protección Social, Resolución 2565 de 2007, por la cual se adoptan unas determinaciones en relación con la cuenta de alto costo, 46.706 Diario Oficial, 31 de julio de 2007. Disponible en: https:/www.minsalud.gov.co/sites/rid/Lists/Biblioteca Digital/RIDE/DE/DIJ/resolucion-2565-2007.pdf. Colombia, Ministerio de la Protección Social, Resolución 3974 de 2009, por la cual se adoptan unas determinaciones en relación con la Cuenta de Alto Costo, 47.516 Diario Oficial, 28 de octubre de 2009. Disponible en: https://docs.supersalud. gov.co/PortalWeb/Juridica/OtraNormativa/R_MPS_3974_2009.pdf. Colombia, Ministerio de Salud, Criterios para identificar patologías de alto costo en Colombia (Bogotá, 2014). 
La ley 100 de 1993 contempla la existencia de copagos y pagos moderadores para el sostenimiento y racionalización en el uso del sistema de salud; sin embargo, la Corte Constitucional ha advertido que bajo ninguna circunstancia estos pagos $^{89}$ se pueden convertir en barreras de acceso ${ }^{90}$ para estos pacientes por considerarlos sujetos de especial protección constituciona $1^{91}$. Por esta razón, ha definido dos escenarios en los que se debe inaplicar la norma que regulan estos pagos, por las condiciones económicas del paciente y de su familia y por excepciones que contempla la propia normativa ${ }^{92}$. No obstante lo dispuesto por la Corte, las EPS no siempre se acogen a esto, pues cobran a sus usuarios con enfermedades de alto costo los copagos ${ }^{93}$, como lo evidencia el magistrado Aquiles Arrieta ${ }^{94} \mathrm{de}$ la Corte Constitucional, al señalar que estas situaciones de cobro indebido son comunes y que se siguen repitiendo, a pesar de las múltiples sanciones que se han impuesto ${ }^{95}$. En el mismo sentido apunta el doctor Néstor Álvarez ${ }^{96}$, que hay otra problemática muy preocupante, al afirmar que debe pagar cuota moderadora $o$ copago la patología y no el paciente como tal, ya que en el evento en que un paciente de una enfermedad de alto costo se fracture un pie, la EPS argumenta que no corresponde a una patología de "alto costo", por lo tanto, hay que pagar cuota moderadora, que en

89 El artículo el 7 del Acuerdo 260 de 2004 excluye de estos pagos a los pacientes con enfermedades de alto costo; por tanto, están cobijados por esta última excepción. Colombia, Consejo Nacional de Seguridad Social en Salud, CNSSS, Acuerdo 260 de 2004, por el cual se define el régimen de pagos compartidos y cuotas moderadoras dentro del Sistema General de Seguridad Social en Salud, 45.474 Diario Oficial, 27 de febrero de 2004. Disponible en: http://www.alcaldiabogota.gov.co/sisjur/ normas/Norma1.jsp?i=32036

90 Colombia, Defensoría del Pueblo. La tutela y los derechos a la salud y a la seguridad social, 2015 (Defensoría del Pueblo, Bogotá, 2016).

91 Colombia, Corte Constitucional, Sentencia T-611-14, 25 de agosto de 2014, magistrado ponente Jorge Iván Palacio-Palacio. Disponible en: http://www.corteconstitucional.gov.co/relatoria/2014/t-611-14. htm

92 Colombia, Consejo de Estado, Sala de lo Contencioso Administrativo, Sección Quinta, Radicación 11001-03-15-000-2014-04332-00, 5 de febrero de 2015, consejera ponente Lucy Jeannette Bermúdez-Bermúdez. Disponible en: http://consejodeestado.gov.co/documentos/sentencias/ 11001031500020140433200.pdf

93 Los doctores Aquiles Arrieta, magistrado de la Corte Constitucional; Carolina Corcho, MD psiquiatra y vocera de la Mesa Nacional por el Derecho a la Salud; y Néstor Álvarez, representante de pacientes de alto costo y defensor del derecho a la salud.

94 Entrevista realizada en junio de 2016.

95 El doctor Arrieta reconoce que esos usos perversos siguen persistiendo y que es complicado abolirlos, pero ante esta problemática plantea preguntas que podrían ser objeto de otra investigación y que están muy relacionadas: ¿estos cobros indebidos son preocupantes o no? ¿El sistema incentiva a cobrarlos o no? Entrevista realizada en junio de 2016.

96 Entrevista realizada en junio de 2016. 
palabras de este experto, es una "interpretación malvada de la ley por parte de las EPS", a pesar de que la Corte Constitucional y el Consejo de Estado han fijado su posición correctamente al advertir que es el paciente con una determinada patología a quien se le debe categorizar como de alto costo, no la patología.

Los elevados costos de los tratamientos - entre otras situaciones - han abierto la puerta al uso de la acción de tutela, lo cual a su vez ha generado una repercusión en las finanzas de la salud, ya que las tutelas en la mayoría de los casos son resueltas a favor de las pretensiones del paciente ${ }^{97}$.

\section{Recobros al Fondo de Solidaridad y Garantias (Fosyga)}

Según la Fundación para la Educación Superior y el Desarrollo (Fedesarrollo), cuando un juez constitucional concede el amparo solicitado con el argumento de la protección del derecho a la salud, la tutela resulta ser el mecanismo idóneo para garantizar los servicios y bienes contemplados en el POS, por ser una reclamación natural de los usuarios de los regímenes contributivo y subsidiado para lograr la efectividad del derecho a la salud ${ }^{98}$. Esta posibilidad no se predica cuando las acciones de amparo están encaminadas a solicitar atenciones No POS $^{99}$, debido a que en estos casos el juez constitucional desencadena dos resultados negativos en cuanto a los recobros al Fosyga $^{100}$, el primero de ellos financiero en términos de disposición

97 Colombia, Defensoría del Pueblo. La tutela y los derechos a la salud y a la seguridad social, 2015 (Defensoría del Pueblo, Bogotá, 2016).

98 JaIRo NúÑEZ \& JuAN GonZaLo ZAPATA, La sostenibilidad financiera del sistema de salud colombiano: dinámica del gasto y principales retos de cara al futuro (Centro de Investigación Económica y Social, Fundación para la Educación Superior y el Desarrollo, Fedesarrollo, Bogotá, 2012). Disponible en: http://adida.org.co/pdf/salud_2012/la_sostenibilidad.pdf

99 Jairo NúÑez \& Juan Gonzalo Zapata, La sostenibilidad financiera del sistema de salud colombiano: dinámica del gasto y principales retos de cara al futuro (Centro de Investigación Económica y Social, Fundación para la Educación Superior y el Desarrollo, Fedesarrollo, Bogotá, 2012).

100 De acuerdo con el artículo 218 de la Ley 100 de 1993 y el artículo 1 del Decreto 1283 de 1996, el Fosyga es una cuenta en la que se centralizan y administran todos los recursos apropiados para la salud en Colombia, es decir, el Fosyga gestionará cuatro subcuentas: compensación interna del régimen contributivo, solidaridad del régimen de subsidios en salud, promoción en salud y seguro de riesgos catastróficos y accidentes de tránsito (Ley 100 de 1993). Esta cuenta está manejada como un encargo fiduciario - con la Resolución 003977 del 9 de septiembre de 2011, el Ministerio de Salud y Protección Social adjudicó ese encargo al Consorcio SAYP. Colombia, Decreto 1283 de 1996, por el cual se reglamenta el funcionamiento del Fondo de Solidaridad y Garantía del Sistema General de Seguridad Social en Salud, 42.840 Diario Oficial, 25 de julio de 1996. Disponible en: http://www. 
de recursos y alteración del modelo asegurador de la Ley 100 de $1993^{101}$ y el segundo, económico sobre los incentivos de los usuarios y jueces ${ }^{102}$. Esta situación se da porque esta ley estipuló una forma de aseguramiento individual obligatorio, que está compuesto por unos afiliados, un riesgo, una prima, una cobertura, un patrimonio técnico y una reserva técnica, esta última figura nace de los recursos pagados en las primas cobradas a los usuarios y que son apartados para cubrir los riesgos que se quieren conjurar ${ }^{103}$. Como la reserva es un porcentaje del total de las primas no puede congelarse en el sistema, por el contrario, debe ser líquida para que se invierta y crezca, así al momento de un siniestro, habrá cómo pagar su totalidad ${ }^{104}$.

Cuando se reclama un siniestro por fuera de la cobertura que proporciona el POS, ni la reserva ni el patrimonio técnicos del SGSSS — esto es el FOSYGA - están destinados a cubrir esas enfermedades ${ }^{105}$, por lo que los usuarios recurren a las acciones de tutela para que los jueces constitucionales protejan sus derechos fundamentales, incluso con el costo de desatender la forma de aseguramiento $^{106}$. La gravedad en el desvío de estos recursos no puede arreglarse a punta de mandatos jurisprudenciales ni legales, porque los recobros de órdenes de tutela seguirán existiendo y por lo tanto, los recursos del Fosyga permanecerán congelados y con esto, no habrá dinero para pagar oportunamente las atenciones médicas de las EPS en razón del No POS.

suin-juriscol.gov.co/viewDocument.asp?id=1258854. Colombia, Ministerio de Salud y Protección Social, Resolución 003977 del 9 de septiembre de 2011, por la cual se adiciona el presupuesto del mecanismo único de recaudo y giro de los recursos que financian y cofinancian la Unidad de Pago por Capitación del Régimen Subsidiado para la vigencia fiscal de 2013. Disponible en: https://www. minsalud.gov.co/Normatividad_Nuevo/Resoluci\%C3\%B3n\%203977\%20de\%202013.pdf

101 JaIRo NúÑEZ \& JuAn GonZalo ZAPATA, La sostenibilidad financiera del sistema de salud colombiano: dinámica del gasto y principales retos de cara al futuro (Centro de Investigación Económica y Social, Fundación para la Educación Superior y el Desarrollo, Fedesarrollo, Bogotá, 2012).

102 JaIRo NúÑez \& JuAn GonZalo Zapata, La sostenibilidad financiera del sistema de salud colombiano: dinámica del gasto y principales retos de cara al futuro (Centro de Investigación Económica y Social, Fundación para la Educación Superior y el Desarrollo, Fedesarrollo, Bogotá, 2012).

103 CARMEn Solorio, Seguridad social en salud (Organización Internacional del Trabajo, OIT, Ginebra, 2001).

104 CARMEN Solorio, Seguridad social en salud (Organización Internacional del Trabajo, OIT, Ginebra, 2001).

105 Augusto Acosta, Finanzas en el sistema de seguridad social de salud en Colombia, Foro En busca de las mejores iniciativas de salud que contribuyan al crecimiento económico del país. Portafolio (Bogotá, 23 de octubre de 2013).

106 Augusto Acosta, Finanzas en el sistema de seguridad social de salud en Colombia, Foro En busca de las mejores iniciativas de salud que contribuyan al crecimiento económico del país. Portafolio (Bogotá, 23 de octubre de 2013). 
No obstante, la desviación de recursos que se ordena desde una sentencia de tutela no solo desnaturaliza el sistema de aseguramiento de la Ley 100 de 1993, sino que también tiene repercusiones fiscales gravosas, que se reflejan en el hecho de que los gastos adicionales generados por sentencias en salud equivalen en promedio a $1 \%$ del Producto Interno Bruto (PIB) de salud ${ }^{107}$. Este porcentaje del PIB puede parecer insustancial en términos abstractos, pero esa simple unidad es representación de una mayor presión fiscal para toda la sociedad $^{108}$, afirmación que se basa en que los recursos de los que deliberadamente dispone el juez a partir de sus razonamientos legales, son la acumulación de una porción de una partida presupuestal para la salud, proveniente del Sistema General de Participaciones (SGP), una proporción de las cotizaciones que hacen los afiliados al régimen contributivo, la Unidad de Pago por Capitación (UPC) que pagan las EPS y el recaudo hecho por el Seguro Obligatorio de Accidentes de Tránsito (SOAT).

En materia de recobros por eventos No POS, la línea ha sido progresiva con el paso de los años, pues creció a una tasa anual promedio de $87 \%$ entre 2005 y 2010, hasta llegar a $\$ 2,35$ billones en $2010^{109}$. Sin embargo, entre 2011 y 2012, el Ministerio de Salud y Protección Social puso en marcha un paquete de medidas ${ }^{110}$, con las que logró cambiar la tendencia de los recobros, al pasar de pagar $\$ 2,03$ billones en 2011 a $\$ 1,74$ billones en 2012, lo que generó una reducción de alrededor de $\$ 320.000$ millones en 2011 en comparación con 2010 y $\$ 290.000$ millones en 2012 frente a lo registrado en 2011. En 2013 se llegó a la suma de \$1,69 billones ${ }^{111}$ y en 2014 fue de

107 Christian Jaramillo, Impacto fiscal de tutelas y sentencias de la Corte Constitucional en los temas de salud y pensiones (Banco Interamericano de Desarrollo, BID, Bogotá, 2011).

108 Christian Jaramillo, Impacto fiscal de tutelas y sentencias de la Corte Constitucional en los temas de salud y pensiones (Banco Interamericano de Desarrollo, BID, Bogotá, 2011).

109 Ministerio de Salud y Protección Social, Respuesta al derecho de petición 201433201779521, del 15 de diciembre de 2014, del Ministerio de Salud, con ocasión al derecho de petición instaurado por la profesora Clara Viviana Plazas-Gómez, de la Facultad de Jurisprudencia de la Universidad del Rosario, radicado interno AJH001, del 2 de diciembre de 2014 (Bogotá, 2015).

110 Mecanismos de política pública e instrumentos administrativos, encaminados a regular los precios de medicamentos - representan cerca del $77 \%$ de las tecnologías recobradas - y la optimización de los requisitos para el trámite del recobro. Ministerio de Salud y Protección Social, Respuesta al derecho de petición 201433201779521, del 15 de diciembre de 2014, del Ministerio de Salud, con ocasión al derecho de petición instaurado por la profesora Clara Viviana Plazas-Gómez, de la Facultad de Jurisprudencia de la Universidad del Rosario, radicado interno AJH0O1, del 2 de diciembre de 2014 (Bogotá, 2015).

111 \$2.371 billones, incluyendo aprobación de recobros sin constancia de cancelación futura, que fue de aproximadamente de $\$ 600.000$ millones para 2013. Ministerio de Salud y Protección Social, 
\$2,13 billones, incluyendo la aprobación de recobros sin constancia de cancelación futura, aproximadamente de $\$ 842.000$ millones $^{112}$.

El daño a la configuración inicial del SGSSS reveló un inconveniente más difícil de administrar: la aparición de incentivos perversos dentro del modelo de salud ${ }^{113}$, pues al pagar sus cuotas mensuales de afiliación, los usuarios del sistema están cubiertos en ciertos riesgos por el POS; a pesar de lo anterior, al recurrir a las acciones de tutela pueden lograr más cobertura ${ }^{114}$, sin que esto represente una mayor prima individual ${ }^{115}$. Debido a que la restricción de presupuesto se mantiene individualmente y a que la distribución entre toda la sociedad de una mayor carga fiscal puede llegar a ser individualmente despreciable, siempre habrá más beneficios cuando se utilizan recursos legales para estirar los servicios que el SGSSS presta por medio del POS.

Estos incentivos perversos revelan el otro resultado negativo enunciado por Fedesarrollo: las consecuencias económicas ${ }^{116}$. La recurrente utilización de las tutelas se remonta al nacimiento del SGSSS, ya que mediante esta acción constitucional se cobraban los servicios y bienes No POS que los usuarios solicitaban a las EPS ${ }^{117}$, cuya utilización se ubicaba como el 5\% del total de recobros del Fosyga hasta entrada la década de $2000^{118}$. En la década de 2000

Respuesta - Derecho de petición (Bogotá, 2015). Ministerio de Salud y Protección Social, Respuesta al derecho de petición 201433201779521, del 15 de diciembre de 2014, del Ministerio de Salud, con ocasión al derecho de petición instaurado por la profesora Clara Viviana Plazas-Gómez, de la Facultad de Jurisprudencia de la Universidad del Rosario, radicado interno AJH001, del 2 de diciembre de 2014 (Bogotá, 2015).

112 Ministerio de Salud y Protección Social, Cifras financieras del sector salud - Boletín 11 (Bogotá, julio-agosto de 2015). Disponible en: https://www.minsalud.gov.co/sites/rid/Lists/BibliotecaDigital/ RIDE/VP/FS/cifras-financieras-del-sector-salud\%20-boletin-numero-11.pdf

113 Colombia, Ministerio de Salud y Protección Social, Estudio sobre el modo de gestionar la salud en Colombia (Bogotá). Disponible en: https:/www.minsalud.gov.co/Documentos\%20y\%20Publicaciones/ Estudio\%20sobre\%20el\%20modo\%20de\%20gestionar\%20la\%20salud\%20en\%20Colombia.pdf

114 Diego Eduardo LóPez-Medina, Sistema de salud y derecho a la salud. Historia de su interrelación en la jurisprudencia constitucional, artículo presentado en el congreso Contexto Económico y Jurisprudencial del Sistema de Salud, 25 de junio de 2008 (Bogotá, 2008).

115 Sergio Clavijo, Fallos y fallas económicas de las altas cortes: el caso de Colombia 1991-2000, 173 Borradores de Economía, 1-42 (2001).

116 JAIRO NúÑEZ \& JuAN GONZALO ZAPATA, La sostenibilidad financiera del sistema de salud colombiano: dinámica del gasto y principales retos de cara al futuro (Centro de Investigación Económica y Social, Fundación para la Educación Superior y el Desarrollo, Fedesarrollo, Bogotá, 2012).

117 Natalia SAlazar-Ferro, El régimen de seguridad social en salud: problemas financieros, medidas adoptadas y retos para el futuro próximo, 6 Notas Fiscales, Ministerio de Hacienda y Crédito Público (marzo de 2011). Disponible en: http://www.minhacienda.gov.co/HomeMinhacienda/ShowProper ty?nodeId=\%2FOCS\%2FMIG_14646612.PDF\%2F\%2FidcPrimaryFile\&revision=latestreleased

118 Fedesarrollo indica que el porcentaje restante de recobros que se hacían al Fosyga corría por cuenta 
se evidenció un crecimiento exponencial del uso de la tutela, que se mantuvo hasta 2008 por tratarse de la vía más económica para recobrar al Fosyga, si se comparaba con un trámite ante el Comité Técnico Científico (CTC). La favorabilidad en la concesión de la tutela siempre ha sido bastante amplia, para 2014 se situó en $83,16 \%$ en la primera instancia ${ }^{119}$, por la naturaleza del fallo de tutela y la disposición de recursos que trae inmerso, que hace que el juez presuma que siempre hay recursos para garantizar el derecho a la salud ${ }^{120}$. A partir de 2009, el uso de la acción de tutela como principal ordenador del gasto en materia de recobros disminuyó y los CTC tomaron una mayor preponderancia. De los 2.646.164 recobros presentados durante ese año, 1.597.476 fueron tramitados por los CTC y 1.048.688 por vía tutela, tendencia que se mantuvo hasta 2012. En 2013 del total de los recobros presentados, el $84 \%$ fue por medio de los CTC y el 16\% de tutelas ${ }^{121}$, situación que se explica por la reglamentación ${ }^{122}$ de los

de los Comités Técnico-Científicos (CTC), entidades conformadas por un representante de los usuarios, uno de las Instituciones Prestadoras de Salud (IPS) y uno de la entidad administradora de planes de beneficios. Este CTC estará encargado de hacer los recobros al Fosyga por cuenta de medicamentos y tratamientos. Los últimos cambios en esta figura fueron introducidos por la Ley 1438 de 2011. Jairo NúÑEZ \& JuAn Gonzalo Zapata, La sostenibilidad financiera del sistema de salud colombiano: dinámica del gasto y principales retos de cara al futuro (Centro de Investigación Económica y Social, Fundación para la Educación Superior y el Desarrollo, Fedesarrollo, Bogotá, 2012). Colombia, Ley 1438 de 2011, por medio de la cual se reforma el Sistema General de Seguridad Social en Salud y se dictan otras disposiciones, 47.957 Diario Oficial, 19 de enero de 2011. Disponible en: http://www.secretariasenado.gov.co/senado/basedoc/ley_1438_2011.html

119 Colombia, Defensoría del Pueblo, La tutela y los derechos a la salud y a la seguridad social, 2014 (Defensoría del Pueblo, Bogotá, 2015).

120 Sergio Clavijo, Fallos y fallas económicas de las altas cortes: el caso de Colombia 1991-2000, 173 Borradores de Economía, 1-42 (2001).

121 Ministerio de Salud y Protección Social, Cifras financieras del sector salud - Boletín 11 (Bogotá, julio-agosto de 2015). Disponible en: https://www.minsalud.gov.co/sites/rid/Lists/BibliotecaDigital/ RIDE/VP/FS/cifras-financieras-del-sector-salud\%20-boletin-numero-11.pdf

122 Los Comités Técnicos Científicos se reglamentaron mediante Resolución 003099 de 2008, derogada por el artículo 27 de la resolución 548 de 2010 y el artículo 25 de la resolución 458 de 2013. Salvo lo dispuesto en sus artículos 1 al 8. Colombia, Ministerio de la Protección Social, Resolución 003099 de 2008, por la cual se reglamentan los Comités Técnico-Científicos y se establece el procedimiento de recobro ante el Fondo de Solidaridad y Garantía, Fosyga, por concepto de suministro de medicamentos, servicios médicos y prestaciones de salud no incluidos en el Plan Obligatorio de Salud, POS, autorizados por Comité Técnico-Científico y por fallos de tutela, 47.088 Diario Oficial, 21 de agosto de 2008. Disponible en: http://www.alcaldiabogota.gov.co/sisjur/normas/Norma1.jsp?i=32044. Colombia, Ministerio de la Protección Social, Resolución 548 de 2010, por la cual se reglamentan los Comités Técnico-Científicos, se establece el procedimiento de radicación, reconocimiento y pago de recobros ante el Fondo de Solidaridad y Garantía -Fosyga- y se dictan otras disposiciones aplicables durante el período de transición de que trata el artículo 19 del Decreto Legislativo 128 de 2010, 47.621 Diario Oficial, 12 de febrero de 2010. Disponible en: http://www.alcaldiabogota.gov.co/ sisjur/normas/Norma1.jsp?i=38915\#27. Colombia, Ministerio de la Protección Social, Resolución 458 de 2013, por la cual se unifica el procedimiento de recobro ante el Fondo de Solidaridad y Garantía (Fosyga) y se dictan otras disposiciones, 48.712 Diario Oficial, 22 de febrero de 2013. Disponible 
Comités Técnico-Científicos ${ }^{123}$ y la declaración de constitucionalidad ${ }^{124}$ de la expresión consagrada en literal j) del artículo 14 de la Ley 1122 de 2007 "125, que expresa: "Si la EPS no estudia oportunamente tales solicitudes ni las tramita ante el respectivo Comité y se obliga a la prestación de los mismos mediante acción de tutela, los costos serán cubiertos por partes iguales entre las EPS y el Fosyga".

La Sentencia T-760-08 reguló los recobros de los regímenes contributivo y subsidiado ${ }^{126}$, al tiempo que definió sus responsables e incluso los mecanismos administrativos para su recobro. También permitió que los CTC, que hasta ese momento solo eran utilizados para medicamentos, fueran admitidos para procedimientos y servicios, incluyendo cirugías, terapias...127.

\section{TUTELAS EN SALUD: ENTRE EL GARANTISMO Y EL ACTIVISMO}

Las implicaciones financieras derivadas de las decisiones tomadas en materia de tutela, normalmente generan tensión entre el ámbito funcional de la jurisdicción constitucional, específicamente de la Corte Constitucional y los demás órganos del poder público en Colombia $^{128}$. Por las manos del máximo tribunal constitucional

en: http://www.alcaldiabogota.gov.co/sisjur/normas/Norma1.jsp?i=52011

123 Junto con la normativa y la posibilidad de afectar las finanzas de las EPS, se ha empezado a dar mayor uso a los Comités Técnicos Científicos (CTC), que precisamente fueron creados para que los ciudadanos tengan un medio más directo y expedito para acceder al derecho a la salud.

124 Colombia, Corte Constitucional, Sentencia C-316-08, 9 de abril de 2008, magistrado ponente Jaime Córdoba-Triviño. Disponible en: http://www.corteconstitucional.gov.co/relatoria/2008/c-316-08.htm. Colombia, Corte Constitucional, Sentencia C-463-08, 14 de mayo de 2008, magistrado ponente Jaime Araujo-Rentería. Disponible en: http://www.corteconstitucional.gov.co/relatoria/2008/c-463-08.htm

125 Colombia, Ley 1122 de 2007, por la cual se hacen algunas modificaciones en el Sistema General de Seguridad Social en Salud y se dictan otras disposiciones, 46.506 Diario Oficial, 9 de enero de 2007. Disponible en: http://www.secretariasenado.gov.co/senado/basedoc/ley_1122_2007.html. La norma fue derogada por el artículo 145 de la Ley 1438 de 2011.

126 "El régimen subsidiado es el conjunto de normas que orienta y rige la afiliación de la población sin capacidad de pago al Sistema General de Seguridad Social en Salud. Se encuentran afiliadas a este régimen los núcleos familiares sin capacidad de pago, quienes han sido identificadas (mediante la encuesta SISBEN) como población pobre y vulnerable. La cotización de estas personas es pagada, parcial o totalmente, por el Estado a una Administradora del Régimen Subsidiado (ARS)". Tipos de régimen de salud en Bogotá. Disponible en: http://institutodeestudiosurbanos.info/endatos/0200/02020 -salud/docs/TRSB.pdf

127 JAIRo NúÑEZ \& JuAn GonZalo Zapata, La sostenibilidad financiera del sistema de salud colombiano: dinámica del gasto y principales retos de cara al futuro (Centro de Investigación Económica y Social, Fundación para la Educación Superior y el Desarrollo, Fedesarrollo, Bogotá, 2012).

128 Norberto Apolinar Mendivelso-Pinzón, Las órdenes de tutela frente a la falta de disponibilidad presupuestal de las entidades estatales: análisis en perspectiva constitucional (Tesis de maestría 
han pasado asuntos trascendentales, que representan un esfuerzo muy importante en materia de disponibilidad presupuestal, como el desmonte del UPAC ${ }^{129}$, el tratamiento de la población desplaza$\mathrm{da}^{130}$, la declaración del estado de cosas inconstitucional ${ }^{131}$, órdenes de reubicación de viviendas ${ }^{132}$ y decisiones en materia de salud ${ }^{133}$.

en derecho, Universidad Nacional de Colombia, Bogotá, 2013). Disponible en: http://www.bdigital. unal.edu.co/9907/1/06699844.2013.pdf

129 Colombia, Corte Constitucional, Sentencia C-383-99, 27 de mayo de 1999, magistrado ponente Alfredo Beltrán-Sierra. Disponible en: http://www.corteconstitucional.gov.co/relatoria/1999/c-383-99. htm. Colombia, Corte Constitucional, Sentencia C-700-99, 16 de septiembre de 1999, magistrado ponente José Gregorio Hernández-Galindo. Disponible en: http:/www.corteconstitucional.gov.co/ relatoria/1999/c-700-99.htm. Colombia, Corte Constitucional, Sentencia C-747-99, 6 de octubre de 1999, magistrado ponente Alfredo Beltrán-Sierra. Disponible en: http:/www.corteconstitucional. gov.co/relatoria/1999/c-747-99.htm

130 Colombia, Corte Constitucional, Sentencia T-025-04, 22 de enero de 2014, magistrado ponente Manuel José Cepeda-Espinosa. Disponible en: http://www.corteconstitucional.gov.co/ relatoria/2004/t-025-04.htm

131 Colombia, Corte Constitucional, Sentencia SU-559-97, 6 de noviembre de 1997, magistrado ponente Eduardo Cifuentes-Muñoz. Disponible en: http://www.corteconstitucional.gov.co/relatoria/1997/ su559-97.htm. Colombia, Corte Constitucional, Sentencia SU-090-00, 2 de febrero de 2000, magistrado ponente Eduardo Cifuentes-Muñoz. Disponible en: http://www.corteconstitucional. gov.co/relatoria/2000/su090-00.htm. Colombia, Corte Constitucional, Sentencia T-068-98, 5 de marzo de 1998, magistrado ponente Alejandro Martínez-Caballero. Disponible en: http://www. corteconstitucional.gov.co/relatoria/1998/t-068-98.htm. Colombia, Corte Constitucional, Sentencia T-153-98, 28 de abril de 1998, magistrado ponente Eduardo Cifuentes-Muñoz. Disponible en: http:// www.corteconstitucional.gov.co/relatoria/1998/t-153-98.htm. Colombia, Corte Constitucional, Sentencia T-1695-00, 7 de diciembre de 2000, magistrado ponente Martha Victoria Sáchica-Méndez. Disponible en: http://www.corteconstitucional.gov.co/relatoria/2000/t-1695-00.htm. Colombia, Corte Constitucional, Sentencia T-025-04, 22 de enero de 2014, magistrado ponente Manuel José Cepeda-Espinosa.

132 Colombia, Corte Constitucional, Sentencia T-237-96, 28 de mayo de 1996, magistrado ponente Carlos Gaviria-Díaz. Disponible en: http://www.corteconstitucional.gov.co/ relatoria/1996/t-237-96.htm. Colombia, Corte Constitucional, Sentencia T-626-00, 30 de mayo de 2000, magistrado ponente Álvaro Tafur-Galvis. Disponible en: http://www.corteconstitucional.gov.co/relatoria/2000/T-626-00.htm. Colombia, Corte Constitucional, Sentencia T-325-02, 2 de mayo de 2002, magistrado ponente Jaime Araújo-Rentería. Disponible en: http://www. corteconstitucional.gov.co/relatoria/2002/t-325-02.htm. Colombia, Corte Constitucional, Sentencia T-1216-04, 3 de diciembre de 2004, magistrado ponente Manuel José Cepeda-Espinosa. Disponible en: http://www.corteconstitucional.gov.co/relatoria/2004/t-1216-04.htm. Colombia, Corte Constitucional, Sentencia T-125-08, 14 de febrero de 2008, magistrado ponente Nilson Pinilla-Pinilla. Disponible en: http://www.corteconstitucional.gov.co/relatoria/2008/t-125-08. htm. Colombia, Corte Constitucional, Sentencia T-473-08, 15 de mayo de 2008, magistrada ponente Clara Inés Vargas-Hernández. Disponible en: http://www.corteconstitucional. gov.co/relatoria/2008/t-473-08.htm. Colombia, Corte Constitucional, Sentencia T-432-09, 1 de julio de 2009, magistrado ponente Humberto Nilson Pinilla-Pinilla. Disponible en: http://www. corteconstitucional.gov.co/relatoria/2009/t-432-09.htm. Colombia, Corte Constitucional, Sentencia T-199-10, 23 de marzo de 2010, magistrado ponente Humberto Antonio Sierra-Porto. Disponible en: http://www.corteconstitucional.gov.co/relatoria/2010/t-199-10.htm

133 Colombia, Corte Constitucional, Sentencia SU-480-97, 25 de septiembre de 1997, magistrado ponente Alejandro Martínez-Caballero. Disponible en: http://www.corteconstitucional.gov.co/ relatoria/1997/su480-97.htm. Colombia, Corte Constitucional, Sentencia SU-819-99, 20 de octubre de 1999, magistrado ponente Álvaro Tafur-Galvis. Disponible en: http://www.corteconstitucional. gov.co/relatoria/1999/su819-99.htm. Colombia, Corte Constitucional, Sentencia T-760-98, 7 de 
Las decisiones de tutela adoptadas en pro de los derechos fundamentales no han sido solamente un tema jurídico; cada tutela revisada por la Corte Constitucional, además de comprometer la efectividad real de los derechos subjetivos en disputa ${ }^{134}$, para remediar alguna violación de derechos, mediante la adopción formal que hace el juez de la medida de restablecimiento de la vulneración, también ha entrado en la órbita funcional de las autoridades encargadas de la previsión y ejecución del presupuesto, al ordenar a una autoridad administrativa el despliegue de actuaciones que afectan las finanzas públicas, sin que estuviera estipulada la debida apropiación presupuestal ${ }^{135}$.

Los defensores de las decisiones de la Corte Constitucional sostienen que estas sentencias enaltecen la protección de las libertades individuales, la protección de las poblaciones históricamente discriminadas y la defensa de los derechos sociales. Por su parte, sus críticos argumentan que tienen un alto contenido económico, por ser decisiones de carácter progresista, que se interpretan como una injerencia de la Corte Constitucional en las competencias de

diciembre de 1998, magistrado ponente Antonio Barrera-Carbonell. Disponible en: http://www. corteconstitucional.gov.co/relatoria/1998/t-760-98.htm. Colombia, Corte Constitucional, Sentencia T-1204-00, 14 de septiembre de 2000, magistrado ponente Alejandro Martínez-Caballero. Disponible en: http://www.corteconstitucional.gov.co/relatoria/2000/t-1204-00.htm. Colombia, Corte Constitucional, Sentencia T-648-07, 17 de agosto de 2007, magistrada ponente Clara Inés Vargas-Hernández. Disponible en: http://www.corteconstitucional.gov.co/relatoria/2007/t-648-07.htm. Colombia, Corte Constitucional, Sentencia T-1007-07, 22 de noviembre de 2007, magistrada ponente Clara Inés VargasHernández. Disponible en: http://www.corteconstitucional.gov.co/relatoria/2007/t-1007-07.htm. Colombia, Corte Constitucional, Sentencia T-139-08, 15 de febrero de 2008, magistrada ponente Clara Inés Vargas-Hernández. Disponible en: http://www.corteconstitucional.gov.co/relatoria/2008/t-139-08. htm. Colombia, Corte Constitucional, Sentencia T-144-08, 15 de febrero de 2008, magistrada ponente Clara Inés Vargas-Hernández. Disponible en: http://www.corteconstitucional. gov.co/relatoria/2008/t-144-08.htm. Colombia, Corte Constitucional, Sentencia T-517-08, 22 de mayo de 2008, magistrada ponente Clara Inés Vargas-Hernández. Disponible en: http://www. corteconstitucional.gov.co/relatoria/2008/t-517-08.htm. Colombia, Corte Constitucional, Sentencia T-760-08, 31 de julio de 2008, magistrado ponente José Manuel Cepeda-Espinosa. Colombia, Corte Constitucional, Sentencia T-818-08, 21 de agosto de 2008, magistrada ponente Clara Inés VargasHernández. Disponible en: http://www.corteconstitucional.gov.co/relatoria/2008/t-818-08.htm (...)

134 Norberto Apolinar Mendivelso-Pinzón, Las órdenes de tutela frente a la falta de disponibilidad presupuestal de las entidades estatales: análisis en perspectiva constitucional (Tesis de maestría en derecho, Universidad Nacional de Colombia, Bogotá, 2013).

135 El presupuesto en Colombia es: "un acto del Estado, considerado como un todo, que halla su expresión concreta en la ley o cuerpo normativo emanado del órgano de representación popular competente, mediante el cual se atiende un plan de actuación económica, se informa sobre los recursos parafiscales administrados por las entidades que cobija, se autoriza el monto máximo de los gastos que el Estado puede realizar durante un lapso determinado, con las atenciones que detalladamente se especifican, y se prevén los ingresos necesarios para cubrirlos". Mauricio Alfredo Plazas-Vega, Derecho de la Hacienda Pública y Derecho Tributario, Tomo I ( $3^{\mathrm{a}}$ ed., Editorial Temis, Bogotá, 2016). 
la Rama Legislativa del poder público ${ }^{136}$, del presidente y del Ministerio de Hacienda y Crédito Público ${ }^{137}$, lo que ha provocado un gran impacto en la economía del país, por considerarse decisiones costosas que además "generan una inestabilidad peligrosa en las finanzas públicas que por conducto del déficit fiscal, alteran el normal desenvolvimiento del mercado, la eficiencia económica, el bienestar general y la misma estabilidad política del Estado"138. Algunos detractores consideran que estas sentencias se enmarcan en el denominado activismo judicial ${ }^{139}$, criticado por disminuir el debate democrático, pues los magistrados no tienen la legitimidad suficiente para tomar decisiones de esta índole, además de generar el posible quebrantamiento de la seguridad jurídica ${ }^{140}$. De igual forma, manifiestan que es motivo de preocupación que los magistrados no sean expertos en materia económica y desconozcan el impacto real de sus fallos, pues estos pueden tocar aspectos sensibles como la eficacia del aparato productivo o el desarrollo del mercado de capitales, los cuales deben regirse por las leyes del mercado cuya modificación debe ser sometida a expertos calificados y sofisticados en temas económicos ${ }^{141}$.

Por su parte, el doctor Mauricio A. Plazas considera que la Corte Constitucional ha tergiversado la teoría de Robert Alexy ${ }^{142}$ sobre los derechos fundamentales, en virtud de la cual se deben generar

136 Jairo Andrés Castaño-Peña, Análisis económico del activismo judicial: el caso de la Corte Constitucional Colombiana, 31 Revista Derecho del Estado, 119-160 (Bogotá, 2013). Disponible en: http:// revistas.uexternado.edu.co/index.php/derest/article/view/3606/3786

137 Hugo Palacio-Mejía, En busca de un control constitucional "eficiente", en Memorias del Seminario Corte Constitucional y Economía: una propuesta para los poderes públicos y la sociedad civil (Banco Interamericano de Desarrollo, BID, Universidad de los Andes, Bogotá, 2000).

138 Clara Eugenia López-Obregón, Economía de los derechos (Universidad del Rosario, Dike, Bogotá, 2005).

139 Se entiende por activismo: "decisiones de los órganos de la administración de Justicia que van más allá de la estricta aplicación de la ley, para extender algunos de sus principios a situaciones nunca previstas por el legislador; y ante las que cabe, además, pensar Razonablemente que el legislador no habría actuado en tal dirección en el momento de promulgar la norma”. Francisco CABRILloRodríguez, Un análisis económico de la administración de Justicia: ¿qué maximizan los jueces?, en Derecho y economía, Universidad San Martín de Porres (2011). Texto disponible en: http:// www.derecho.usmp.edu.pe/centro_derecho_economia/revista/febrero_2011/Analisis_Economico_ de_la_Adm._de_Justicia_Dr_Francisco_Cabrillo.pdf

140 Jairo Andrés Castaño-Peña, Análisis económico del activismo judicial: el caso de la Corte Constitucional Colombiana, 31 Revista Derecho del Estado, 119-160 (Bogotá, 2013).

141 Clara Eugenia López-OBRegón, Economía de los derechos (Universidad del Rosario, Dike, Bogotá, 2005).

142 Robert Alexy, Teoría de los derechos fundamentales (Centro de Estudios Constitucionales, CEC, Madrid, 2007). 
vías de protección colectiva de los derechos fundamentales, pero esta tarea no le corresponde al juez constitucional:

Esa construcción amparada en la objetivación, de ninguna manera puede conducir a que el juez constitucional se traduzca en una especie de mesías nacional, que desplace al Congreso y a la Rama Ejecutiva del poder público y asuma las condiciones de una especie de héroe mítico, algo así como un llanero solitario, un adalid que se presenta ante el país como el que va a solucionar todos los problemas $(\ldots)^{143}$.

Las providencias referentes al derecho a la salud representan la interpretación que tiene la Corte Constitucional sobre lo que debe ser un Estado Social de Derecho, sobre el compromiso permanente con todos los usuarios del sistema de salud ${ }^{144}$. La Corte Constitucional se ha caracterizado por definir subreglas de interpretación ${ }^{145}$, que conceden la acción de tutela para regímenes subsidiado y contributivo, en cuanto a tratamientos integrales, medicamentos - incluso los cubiertos por el POS, como el oxígeno o la insulinay citas de medicina especializada ${ }^{146}$.

La acción de tutela es la acción constitucional más recurrida por los colombianos, con un registro de 614.520 tutelas interpuestas en 2015, considerada la cifra más alta desde su creación en 1991. De las 614.520 acciones, $151.213^{147}$ corresponden a los amparos de salud, que evidencian un incremento del $27,84 \%$ con relación a 2014 cuando se utilizó el mecanismo constitucional 118.281 veces -en promedio cada 3 minutos se interpone en Colombia una tutela para reclamar servicios de salud- ${ }^{148}$. El derecho a la salud es el segundo

143 Entrevista al doctor Mauricio Alfredo Plazas-Vega, con uno de los estudiantes del proyecto de investigación Progresividad del gasto público social y su impacto sobre el derecho a la salud (Bogotá, 21 de octubre de 2014).

144 Carlos Mario Molina-Betancur, editor académico, ¿Limitar ofortalecer la Corte Constitucional?, en Corte Constitucional, 10 años: balance y perspectivas (CARlos Mario Molina-Betancur, editor académico, Centro Editorial Universidad del Rosario, Bogotá, 2003).

145 Diego Eduardo López-Medina, Interpretación constitucional (Escuela Judicial Rodrigo Lara Bonilla, Bogotá, 2006). Disponible en: http://www.ejrlb.net/sites/default/files/interpretacion_constitucional. pdf

146 Redacción Salud, Cada cinco minutos hay una nueva tutela de salud en el país, El Tiempo (4 de septiembre de 2013). Disponible en: http://www.eltiempo.com/archivo/documento/CMS-13045163

147 Esa cifra representa el 24,61\% del total de las tutelas interpuestas durante 2015. Colombia, Defensoría del Pueblo, La tutela y los derechos a la salud y a la seguridad social, 2015 (Defensoría del Pueblo, Bogotá, 2016).

148 Colombia, Defensoría del Pueblo, La tutela y los derechos a la salud y a la seguridad social, 2015 (Defensoría del Pueblo, Bogotá, 2016). 
más accionado después del derecho de petición, con un número total de 287.770 tutelas presentadas en 2015 , equivalente al $46,83 \%$, con un incremento de $11,32 \%$ con relación a $2014^{149}$.

Los jueces de primera instancia son mayoritariamente garantistas, cuando se trata de proteger el derecho a la salud, con un porcentaje de favorecimiento de $83,16 \%$ en 2014 y de $83,59 \%$ en $2015^{150}$. Los indicadores de concesión más altos se observaron en los Juzgados de Menores, 91,3\%; Juzgados Civiles del Circuito, 86,91\% y Juzgados de Familia, 86,7\%; mientras que los más bajos se observaron en la Corte Suprema de Justicia, 31\%; en el Consejo Seccional de la Judicatura, 66,45\% y el Consejo de Estado, 71,88\% $0^{151}$.

Las decisiones en materia de salud están ligadas principalmente a la concesión de tratamientos, medicamentos, citas médicas, prótesis e insumos médicos y cirugías ${ }^{152}$, que tienen implicaciones relevantes para el gasto público, como se evidencia en la sentencia T-760-08, por medio de la cual la Corte Constitucional analiza la crisis en el acceso a la salud, con el fin de solucionar el problema financiero de la salud para contribuir a la equidad y buen funcionamiento del sistema. También se profirió como respuesta a la masiva afectación del derecho a la salud en una política pública, que se había convertido en el tema más litigioso en Derecho Constitucional para la época $^{153}$. Además, esta sentencia - aunque no lo dice-declara el estado de cosas inconstitucionales en el sector de la salud, interfiere en las políticas públicas y da una serie de órdenes de gasto público. La Corte Constitucional emitió órdenes concretas y generales que tuvieron importantes implicaciones desde el punto de vista presupuestal, porque se relacionaron con aspectos de carácter es-

149 Colombia, Defensoría del Pueblo, La tutela y los derechos a la salud y a la seguridad social, 2015 (Defensoría del Pueblo, Bogotá, 2016).

150 Lastimosamente, a pesar del alto grado de favorabilidad en primera instancia, los usuarios se ven en la necesidad de interponer desacatos, por no cumplimiento de los fallos. Colombia, Defensoría del Pueblo, La tutela y los derechos a la salud y a la seguridad social, 2015 (Defensoría del Pueblo, Bogotá, 2016).

151 Colombia, Defensoría del Pueblo, La tutela y los derechos a la salud y a la seguridad social, 2015 (Defensoría del Pueblo, Bogotá, 2016).

152 En 2015, las tutelas interpuestas por tratamientos ascendieron a 76.899, por medicamentos 51.795, por citas médicas 34.005 , por prótesis e insumos médicos 34.140 y finalmente por cirugías 28.324 solicitudes. Colombia, Defensoría del Pueblo, La tutela y los derechos a la salud y a la seguridad social, 2015 (Defensoría del Pueblo, Bogotá, 2016).

153 Norberto Apolinar Mendivelso-Pinzón, Las órdenes de tutela frente a la falta de disponibilidad presupuestal de las entidades estatales: análisis en perspectiva constitucional (Tesis de maestría en derecho, Universidad Nacional de Colombia, Bogotá, 2013). 
tructural de la política pública en salud y se dispuso el seguimiento al cumplimento de las decisiones tomadas ${ }^{154}$.

En cumplimiento de la regla básica del gasto, esto es, no gastar más de lo que ingresa a las arcas, el gobierno promovió una reforma constitucional a partir del Acto legislativo 003 de $2011^{155}$, el cual modificó el artículo 334 de la Constitución Política, incluyendo el criterio de sostenibilidad fiscal y el incidente de impacto fiscal ${ }^{156}$. La razón de la modificación es que en Colombia no existía una referencia constitucional expresa ${ }^{157}$ de la sostenibilidad fiscal, que diera a las personas una garantía de homogeneidad, estabilidad y exigibilidad, en cuanto al mantenimiento de las condiciones económicas necesarias para asegurar la plena efectividad de los derechos ${ }^{158}$.

Entre las razones de índole económica que llevaron a la consecución del acto legislativo y que se describen en la exposición de motivos están: 1. El supuesto fáctico de un "escenario económico no favorable", pues en caso de que esta situación ocurra, la idea es que se pueda mantener la política de gasto en el tiempo, de manera que no haya un retroceso en la protección de derechos ${ }^{159}$. 2. Si se tienen que elevar los gastos en relación con el tamaño de la economía (PIB), las tasas de interés pueden elevarse de manera significativa, lo que llevaría a la inhibición de la inversión extranjera y restringiría las mejoras en la productividad ${ }^{160}$. 3. Si el gasto sigue incrementándose $\mathrm{y}$ es insostenible en el tiempo puede llevar a ajustes macroeco-

154 Colombia, Corte Constitucional, Sentencia T-760-08, 31 de julio de 2008, magistrado ponente José Manuel Cepeda-Espinosa.

155 Colombia, Acto legislativo 003 de 2011, por el cual se establece el principio de la sostenibilidad fiscal, 48.117 Diario Oficial, 1 de julio de 2011. Disponible en: http://www.alcaldiabogota.gov.co/ sisjur/normas/Norma1.jsp?i=43214

$156 \mathrm{El}$ incidente de impacto fiscal es un instrumento mediante el cual se busca evaluar los efectos económicos que conllevan los fallos de las altas cortes, con el fin de establecer la forma de cumplimiento de los mismos, pero siendo coherentes con los límites de la hacienda pública. Colombia, Ley 1695 de 2013, por medio de la cual se desarrolla el artículo 334 de la Constitución Política y se dictan otras disposiciones, 49.007 Diario Oficial, 17 de diciembre de 2013. Disponible en: http://www. secretariasenado.gov.co/senado/basedoc/ley_1695_2013.html

157 Antes de la reforma constitucional ya había referencia a la sostenibilidad fiscal en el ordenamiento jurídico, esto es, en la jurisprudencia y en normativa como el Estatuto Orgánico del Presupuesto y la ley 819 de 2003, pero su acatamiento era limitado al no poseer estas jerarquía superior. Colombia, 451 Gaceta del Congreso (15 de julio de 2010). Disponible en: http://www.imprenta.gov.co/gacetap/ gaceta.nivel_3

158 Colombia, $4 \overline{5} 1$ Gaceta del Congreso (15 de julio de 2010).

159 Colombia, 451 Gaceta del Congreso (15 de julio de 2010).

160 Colombia, 451 Gaceta del Congreso (15 de julio de 2010). 
nómicos indeseables por medio de incrementos en la inflación o movimientos fuertes en la tasa de cambio; lo que puede derivar en quiebras, pérdida de riqueza y empobrecimiento correlativo ${ }^{161}$. 4. Si para cubrir el gasto se deben aumentar los niveles de deuda pública como porcentaje del PIB, implicaría una mayor dependencia del financiamiento interno y externo, lo cual en el futuro significaría que una mayor proporción de los ingresos propios del Estado y los gastos inherentes del sector público deban destinarse a pagar el servicio de la deuda pública ${ }^{162}$. 5. Si hay una crisis de los factores económicos derivada del mal manejo de las finanzas, es posible que los mercados financieros cierren la disponibilidad de crédito o endurezcan las condiciones, lo cual desembocaría en situaciones inimaginables de crisis económicas, sociales y políticas ${ }^{163}$.

Tanto el criterio de sostenibilidad fiscal como la regla fiscal ${ }^{164}$ y el incidente de impacto fiscal se consideran instrumentos que imponen restricciones de gasto ligadas a los límites de la Hacienda pública, que no solo deben importar al gobierno sino también a las altas cortes, pues las invita a analizar con profundidad los efectos económicos de sus providencias. Sin embargo, el principio de sostenibilidad fiscal no puede ser un criterio para negar los servicios de salud a ninguna persona que los requiera, ya que la continuación de un tratamiento no puede depender de razones administrativas y mucho menos económicas.

A pesar de la entrada en vigencia de la Ley Estatutaria de Salud, el panorama del derecho a la salud sigue siendo incierto, el déficit del sector a 2015 era de $\$ 5,3$ billones de pesos ${ }^{165}$, además del déficit fiscal de $\$ 30,5$ billones de pesos en $2016^{166}$, lo cual ha imposibilitado la plena implementación del contenido de la ley. Sumado a lo anterior,

\footnotetext{
161 Colombia, 451 Gaceta del Congreso (15 de julio de 2010).

162 Colombia, 451 Gaceta del Congreso (15 de julio de 2010).

163 Colombia, 451 Gaceta del Congreso (15 de julio de 2010).

164 La regla fiscal es una restricción presupuestal intemporal del gobierno, que se adopta para alcanzar objetivos cuantificables de desempeño fiscal, por lo general asociados al balance, al nivel de gasto y/o al nivel de endeudamiento. Luis Ignacio Lozano, Hernán Rincón, Miguel Sarmiento \& Jorge EnRIQUe Ramos, Regla fiscal cuantitativa para consolidar y blindar las finanzas públicas de Colombia, 505 Borradores de Economía (2008). Disponible en: http://www.banrep.gov.co/sites/default/ files/publicaciones/pdfs/borra505.pdf

165 Cifra proporcionada por la Asociación Nacional de Instituciones Financieras, ANIF.

166 Dos años después de la Ley Estatutaria la crisis de la salud sigue igual, Opinión \& Salud, Revista Digital (17 de febrero de 2017). Disponible en: http://www.opinionysalud.com/ley-estatutaria-saludministro-gaviria/
} 
persisten problemas en el acceso y prestación de los servicios en los lugares más apartados de la geografía nacional, pues Colombia ha tratado la salud en los últimos años como una cuestión centralizada y ha desconocido las regiones y el sector rural. 


\section{CONCLUSIóN}

La Acción de Tutela ha sido el mecanismo más utilizado en Colombia, para garantizarles a los ciudadanos el derecho fundamental a la salud. Por medio de la tutela se ha amparado eficazmente la gran mayoría de irregularidades que presenta el Sistema General de Seguridad Social en Salud (SGSSS), en situaciones como servicios No POS y enfermedades de alto costo, que en la mayoría de los casos terminan siendo protegidas por la Corte Constitucional, sin que en algunos casos se dimensione las implicaciones presupuestales y financieras que se generan al Estado.

Sin embargo, no se puede desconocer que las sentencias en salud son el resultado del mal funcionamiento del sistema, que obliga al juez constitucional a intervenir para hacer exigible lo que se entiende por dado. A pesar de que en los últimos años, la asignación presupuestal del sector de la salud ha tenido un notorio incremento, los recursos siguen siendo insuficientes para atender todos los requerimientos de los ciudadanos, situación que no ha permitido la reducción del uso de la acción de tutela.

Algunas de las sentencias que protegen el derecho a la salud, proferidas por la Corte Constitucional, han sido blanco de críticas, por las excesivas implicaciones fiscales que estas representan. Esta - entre otras razones - justificó la modificación del artículo 334 de la Constitución Política y la incorporación del criterio de sostenibilidad fiscal, la regla fiscal y el incidente de impacto fiscal, que permiten modular los efectos económicos de las sentencias, sin que esto conlleve la negación de los servicios de salud.

Aunque la Ley Estatutaria de Salud 1751 de 2015 fortaleció el concepto de la fundamentalidad de la salud y propuso nuevas medidas, como la eliminación del POS y No POS, los CTC y el control a los medicamentos, el balance después de dos años de entrada en vigencia no es alentador. Se puede afirmar, sin demeritar el trabajo que ha venido haciendo el gobierno para lograr la efectividad de la norma, que aún hace falta mucho más compromiso estatal para que por fin se tenga un verdadero Derecho a la Salud en Colombia, que responda con integridad a los principios establecidos en la Ley Estatutaria. 


\section{BIBLIOGRAFíA}

\section{Libros}

Abramovich, Víctor \& Courtis, Christian, Los derechos sociales como derechos exigibles (Trotta, Madrid, 2002).

Alexy, Robert, Teoría de los derechos fundamentales (Centro de Estudios Constitucionales, CEC, Madrid, 2007).

Blanco-Restrepo, Jorge Humberto \& Maya-Mejía, José María, Fundamentos de salud pública (Corporación para Investigaciones Biológicas, CIB, Medellín, 2005).

Calle, Humberto de la; Robledo, Jorge Enrique; Morales, Claudia; Estrada-Villa, Armando; Andia, Oscar; Quevedo-Hernández, Norbey; Avellaneda-Silva, Joan; Sánchez-Herrera, Beatriz; Arias, Wilson \& González, Jorge Iván, Perlas de la corrupción (Debate, Bogotá, 2013).

Colombia, Defensoría del Pueblo, La tutela y los derechos a la salud y a la seguridad social, 2012 (Defensoría del Pueblo, Bogotá, 2013). Disponible en: http://www. consultorsalud.com/sites/consultorsalud/files/La $\% 2520$ Tutela $\% 2520 \mathrm{y} \% 2520 \mathrm{el} \%$ 2520 derecho $\% 2520 \mathrm{a} \% 25201 \mathrm{a} \% 2520$ Salud $\% 25202012 \% 2520-\% 2520$ Informe $\% 252$ 0Defensoria $\% 2520 \mathrm{del} \% 2520$ Pueblo.pdf

Colombia, Defensoría del Pueblo, La tutela y los derechos a la salud y a la seguridad social, 2013 (Defensoría del Pueblo, Bogotá, 2014). Disponible en: http://www. defensoria.gov.co/attachment $/ 605 / 207685 \% 20 \mathrm{La} \% 20$ tutela $\% 20 \mathrm{y} \% 20 \mathrm{el} \% 20$ derecho $\% 20$ a $\% 201 \mathrm{a} \% 20$ salud. $\% 202013 . \% 20$ Definitivo $\% 20 \mathrm{en} \% 20 \mathrm{imprenta}$.pdf

Colombia, Defensoría del Pueblo, La tutela y los derechos a la salud y a la seguridad social, 2014 (Defensoría del Pueblo, Bogotá, 2015). Disponible en: http://www. defensoria.gov.co/public/pdf/LatutelaylosderechosalaSalud.pdf

Colombia, Defensoría del Pueblo, La tutela y los derechos a la salud y a la seguridad social, 2015 (Defensoría del Pueblo, Bogotá, 2016).

Dueñas-Ruiz, Óscar, Acción y procedimiento en la tutela (Librería del Profesional, Bogotá, 2009).

GonzÁlez-Moreno, Beatriz, El Estado social. Naturaleza jurídica y estructura de los derechos sociales (Civitas Ediciones, Madrid, 2014).

Jaramillo, Christian, Impacto fiscal de tutelas y sentencias de la Corte Constitucional en los temas de salud y pensiones (Banco Interamericano de Desarrollo, BID, Bogotá, 2011).

LóPez-Medina, Diego Eduardo, Interpretación constitucional (Escuela Judicial Rodrigo Lara Bonilla, Bogotá, 2006). Disponible en: http://www.ejrlb.net/sites/default/ files/interpretacion_constitucional.pdf

López-Obregón, Clara Eugenia, Economía de los derechos (Universidad del Rosario, Dike, Bogotá, 2005).

Molina-Betancur, Carlos Mario, editor académico, Corte Constitucional, 10 años: balance y perspectivas (Centro Editorial Universidad del Rosario, Bogotá, 2003). 
Plazas-Vega, Mauricio Alfredo, Derecho de la Hacienda Pública y Derecho Tributario, Tomo I ( $3^{a}$ ed., Editorial Temis, Bogotá, 2016).

Solorio, Carmen, Seguridad social en salud (Organización Internacional del Trabajo, OIT, Ginebra, 2001).

\section{Contribución en obras colectivas}

Abramovich, Víctor \& Courtis, Christian, Hacia la exigibilidad de los derechos económicos, sociales y culturales: estándares internacionales y criterios de aplicación ante los tribunales locales, en La aplicación de los tratados sobre derechos humanos por los tribunales locales, 283-350 (MARTín ABregú, comp., Editores del Puerto, Buenos Aires, 1997).

Molina-Betancur, Carlos Mario, editor académico, ¿Limitar o fortalecer la Corte Constitucional?, en Corte Constitucional, 10 años: balance y perspectivas (CARLOS Mario Molina-Betancur, editor académico, Centro Editorial Universidad del Rosario, Bogotá, 2003).

Palacio-Mejía, Hugo, En busca de un control constitucional "eficiente", en Memorias del Seminario Corte Constitucional y Economía: una propuesta para los poderes públicos y la sociedad civil (Banco Interamericano de Desarrollo, BID, Universidad de los Andes, Bogotá, 2000).

\section{Revistas}

Ahumada, Consuelo, Política social y reforma de salud en Colombia, 7 Papel Politico, 9-35 (1998).

Benavides-Luna, Manuel; Torres-Navas, Adriana \& Arias-Barrera, Carlos, Aspectos sobre tratamiento, detección y costos en el enfoque de la hipertensión arterial pulmonar, 25 Revista Colombiana de Neumología, 3, 133-135 (2013). Disponible en: http://revistas.asoneumocito.org/index.php/rcneumologia/article/ viewFile/104/100

Cabrillo-Rodríguez, Francisco, Un análisis económico de la administración de Justicia: ¿qué maximizan los jueces?, en Derecho y economía, Universidad San Martín de Porres (2011). Texto disponible en: http://www.derecho.usmp.edu.pe/ centro_derecho_economia/revista/febrero_2011/Analisis_Economico_de_la_ Adm._de_Justicia_Dr_Francisco_Cabrillo.pdf

Carbonell, Miguel, Eficacia de la Constitución y derechos sociales: esbozo de algunos problemas, 6 Estudios Constitucionales, 2, $43-71$ (2008). Disponible en: http:// www.redalyc.org/articulo.oa?id=82060203

Castaño-Peña, Jairo Andrés, Análisis económico del activismo judicial: el caso de la Corte Constitucional Colombiana, 31 Revista Derecho del Estado, 119-160 (Bogotá, 2013). Disponible en: http://revistas.uexternado.edu.co/index.php/derest/article/ view/3606/3786

Clavijo, Sergio, Fallos y fallas económicas de las altas cortes: el caso de Colombia 19912000, 173 Borradores de Economía, 1-42 (2001). Disponible en: http://www.banrep. 
gov.co/docum/ftp/borra173.pdf

David, Inés Milena; Medina, Ana María \& Martínez, Elkin, Enfermedades de alto costo en afiliados a un sistema institucional de aseguramiento y prestación de servicios de salud, 24 Revista Facultad Nacional de Salud Pública, 2, 98-104 (2006). Disponible en: https://aprendeenlinea.udea.edu.co/revistas/index.php/ fnsp/article/view/249/178

Gallardo-Solarte, Karina; Benavides-Acosta, Fanny Patricia \& Rosales-Jiménez, Rosario, Costos de la enfermedad crónica no transmisible: la realidad colombiana, 14 Revista Ciencias de la Salud, 1, 103-114 (2016). Disponible en: http://revistas. urosario.edu.co/index.php/revsalud/article/view/4596

Gamboa, Óscar; Buitrago, Lina Angélica; Lozano, Teófilo; Dieleman, Sabrina, Gamboa, Carlos; León-Guzmán, Érika; Gila, Milena \& Fuentes, Juan, Costos directos de la atención del cáncer de mama en Colombia, 20 Revista Colombiana de Cancerología, 2, 52-60 (2016). Disponible en: http://www.elsevier.es/es-revistarevista-colombiana-cancerologia-361-articulo-costos-directos-atencion-delcancer-S0123901516300014

Gernigon, Bernard; Odero, Alberto \& Guido, Horacio, Principios de la Oit sobre el derecho a la huelga, 117 Revista Internacional del Trabajo, 4, 1-64 (1998). Disponible en: https://www.fim-musicians.org/wp-content/uploads/right_to_strike_es.pdf

Lozano, Luis Ignacio; Rincón, Hernán; Sarmiento, Miguel \& Ramos, Jorge Enrique, Regla fiscal cuantitativa para consolidar y blindar las finanzas públicas de Colombia, 505 Borradores de Economía (2008). Disponible en: http://www.banrep. gov.co/sites/default/files/publicaciones/pdfs/borra505.pdf

SAlazAr-Ferro, Natalia, El régimen de seguridad social en salud: problemas financieros, medidas adoptadas y retos para el futuro próximo, 6 Notas Fiscales, Ministerio de Hacienda y Crédito Público (marzo de 2011). Disponible en: http://www. minhacienda.gov.co/HomeMinhacienda/ShowProperty?nodeId $=\% 2 \mathrm{FOCS} \% 2$ FMIG_14646612.PDF\%2F\%2FidcPrimaryFile\&revision=latestreleased

\section{Tesis}

Belalcázar-Peña, Isabel Eugenia, La equidad en el plan obligatorio de salud colombiano: una visión comparada (Tesis de maestría, Universidad Nacional de Colombia, Bogotá, 2013). Disponible en: http://www.bdigital.unal.edu.co/9019/1/isabeleug eniabelalcazarpe $\% \mathrm{C} 3 \%$ B1a.2012.pdf

Mendivelso-Pinzón, Norberto Apolinar, Las órdenes de tutela frente a la falta de disponibilidad presupuestal de las entidades estatales: análisis en perspectiva constitucional (Tesis de maestría en derecho, Universidad Nacional de Colombia, Bogotá, 2013). Disponible en: http://www.bdigital.unal.edu. co/9907/1/06699844.2013.pdf 


\section{Documentos, informes, ponencias, reportes}

Acosta, Augusto, Finanzas en el sistema de seguridad social de salud en Colombia, Foro En busca de las mejores iniciativas de salud que contribuyan al crecimiento económico del país. Portafolio (Bogotá, 23 de octubre de 2013).

Arbeláez-Rudas, Mónica, Derecho a la salud en Colombia: el acceso a los servicios del Sistema General de Seguridad Social (Centro de Investigación y Educación Popular, CINEP, Bogotá, 2006).

Asociación Colombiana de Empresas de Medicina Integral, ACEMI, Cifras e indicadores del Sistema de Salud - 2015 (Asociación Colombiana de Empresas de Medicina Integral, ACEMI, Bogotá, 2015). Disponible en: https://acemi.org.co/index.php/ acemi-defecto/9-actualidad/620-cifras-e-indicadores-del-sistema-de-saludpublicacion-2015

Colombia, Ministerio de Salud, Criterios para identificar patologías de alto costo en Colombia (Bogotá, 2014). Disponible en: https://www.minsalud.gov.co/sites/rid/ Lists/BibliotecaDigital/RIDE/INEC/CAC/ALTO_COSTO_FINAL_070911.pdf

Colombia, Ministerio de Salud y Protección Social, Estudio sobre el modo de gestionar la salud en Colombia (Bogotá). Disponible en: https://www.minsalud.gov.co/ Documentos $\% 20 \mathrm{y} \% 20 \mathrm{Publicacione} /$ Estudio $\% 20$ sobre $\% 20 \mathrm{el} \% 20 \operatorname{modo} \% 20$ de $\% 20$ gestionar $\% 201 \mathrm{a} \% 20$ salud $\% 20$ en $\% 20$ Colombia.pdf

López-Medina, Diego Eduardo, Sistema de salud y derecho a la salud. Historia de su interrelación en la jurisprudencia constitucional, artículo presentado en el congreso Contexto Económico y Jurisprudencial del Sistema de Salud, 25 de junio de 2008 (Bogotá, 2008).

Morales-Sánchez, Luis Gonzalo, El financiamiento del sistema de seguridad social en salud en Colombia (LC/L.1037, Comisión Económica para América Latina y el Caribe, CEPAL, Santiago de Chile, 1997). Disponible en: http://archivo.cepal. org/pdfs/1997/S9700142.pdf

NúÑEZ, JAIRo \& ZAPATA, JuAn GonZAlo, La sostenibilidad financiera del sistema de salud colombiano: dinámica del gasto y principales retos de cara al futuro (Centro de Investigación Económica y Social, Fundación para la Educación Superior y el Desarrollo, Fedesarrollo, Bogotá, 2012). Disponible en: http://adida.org.co/pdf/ salud_2012/la_sostenibilidad.pdf

Organización Internacional del Trabajo, OIT, Libertad sindical y negociación colectiva - Estudio general de la Comisión de expertos en Aplicación de Convenios y Recomendaciones, Informe III (parte 4B) 69 Conferencia Internacional del Trabajo, CIT (OIT, Ginebra, 1983).

Zagarra-Cayón, Mauricio \& Jaramillo, Pablo, Actualización legal. La Corte Constitucional publicó la Sentencia C-313 de 2014 que verificó la constitucionalidad de la Ley Estatutaria de Salud (Norton Rose Fulbright, Bogotá, noviembre de 2014). Disponible en: http://www.nortonrosefulbright.com/files/lacorte-constitucional-publico-la-sentencia-c-313-de-2014-que-verifico-laconstitucionalidad-de-la-ley-estatutaria-de-salud-pdf-45kb-123085.pdf 


\section{Tratados internacionales}

Organización de Naciones Unidas, Consejo Económico y Social, Comité de Derechos Económicos, Sociales y Culturales, CESCR, Observación General 14 del Pacto Internacional de Derechos Económicos, Sociales y Culturales, PIDESC, E/C.12/2000/4, 11 de agosto de 2000. Disponible en: http://www.acnur.org/t3/ fileadmin/Documentos/BDL/2001/1451.pdf

Organización de Naciones Unidas, Pacto Internacional de Derechos Económicos, Sociales y Culturales, DESC, Asamblea General, Resolución 2200 A (XXI), 16 de diciembre de 1966. Disponible en: http://www.ohchr.org/SP/ProfessionalInterest/ Pages/CESCR.aspx

\section{Normatividad colombiana}

Colombia, Acto legislativo 003 de 2011, por el cual se establece el principio de la sostenibilidad fiscal, 48.117 Diario Oficial, 1 de julio de 2011. Disponible en: http://www.alcaldiabogota.gov.co/sisjur/normas/Norma1.jsp?i=43214

Colombia, Constitución Política de 1991, versión corregida, 116 Gaceta Constitucional, 20 de julio de 1991. Disponible en: http://www.secretariasenado.gov.co/index. php/constitucion-politica

Colombia, 451 Gaceta del Congreso (15 de julio de 2010). Disponible en: http://www. imprenta.gov.co/gacetap/gaceta.nivel_3

Colombia, Decreto 111 de 1996, por el cual se compilan la Ley 38 de 1989, la Ley 179 de 1994 y la Ley 225 de 1995 que conforman el Estatuto Orgánico del Presupuesto, 42.692 Diario Oficial, 18 de enero de 1996. Disponible en: http:// www.secretariasenado.gov.co/senado/basedoc/decreto_0111_1996.html

Colombia, Decreto 1283 de 1996, por el cual se reglamenta el funcionamiento del Fondo de Solidaridad y Garantía del Sistema General de Seguridad Social en Salud, 42.840 Diario Oficial, 25 de julio de 1996. Disponible en: http://www.suin-juriscol. gov.co/viewDocument.asp?id=1258854

Colombia, Decreto 2699 de 2007, por el cual se establecen algunas normas relacionadas con el Sistema General del Seguridad Social en Salud y se dictan otras disposiciones, 46.688 Diario Oficial, 13 de julio de 2007. Disponible en: http:// www.suin-juriscol.gov.co/viewDocument.asp?id=1482079

Colombia, Decreto 705 de 2016, por el cual se establecen disposiciones sobre el proceso de regulación de precios de medicamentos a nivel nacional, 49.857 Diario Oficial, 27 de abril de 2016. Disponible en: http://www.suin-juriscol.gov.co/viewDocument. asp?id $=30020258$

Colombia, Ley 90 de 1946, por la cual se establece el seguro social obligatorio y se crea el Instituto Colombiano de Seguros Sociales, 23.112 Diario Oficial, 7 de enero de 1947. Disponible en: http://www.suin-juriscol.gov.co/viewDocument. asp?id=1631247

Colombia, Ley 100 de 1993, por la cual se crea el sistema de seguridad social integral y se dictan otras disposiciones, 41.148 Diario Oficial, 23 de diciembre de 
1993. Disponible en: http://www.secretariasenado.gov.co/senado/basedoc/ ley_0100_1993.html

Colombia, Ley 1122 de 2007, por la cual se hacen algunas modificaciones en el Sistema General de Seguridad Social en Salud y se dictan otras disposiciones, 46.506 Diario Oficial, 9 de enero de 2007. Disponible en: http://www.secretariasenado. gov.co/senado/basedoc/ley_1122_2007.html

Colombia, Ley 1438 de 2011, por medio de la cual se reforma el Sistema General de Seguridad Social en Salud y se dictan otras disposiciones, 47.957 Diario Oficial, 19 de enero de 2011. Disponible en: http://www.secretariasenado.gov.co/senado/ basedoc/ley_1438_2011.html

Colombia, Ley 1695 de 2013, por medio de la cual se desarrolla el artículo 334 de la Constitución Política y se dictan otras disposiciones, 49.007 Diario Oficial, 17 de diciembre de 2013. Disponible en: http://www.secretariasenado.gov.co/senado/ basedoc/ley_1695_2013.html

Colombia, Ley Estatutaria 1751 de 2015, por medio de la cual se regula el derecho fundamental a la salud y se dictan otras disposiciones, 49.427 Diario Oficial, 16 de febrero de 2015. Disponible en: http://www.secretariasenado.gov.co/senado/ basedoc/ley_1751_2015.html

Colombia, Ley 1753 de 2015, por la cual se expide el Plan Nacional de Desarrollo 2014-2018 “Todos por un nuevo país", 49.538 Diario Oficial, 9 de junio de 2015. Disponible en: http://www.secretariasenado.gov.co/senado/basedoc/ ley_1753_2015.html

Colombia, Ley 1769 de 2015, por la cual se decreta el presupuesto de rentas y recursos de capital y Ley de Apropiaciones para la vigencia fiscal del 1 de enero al 31 de diciembre de 2016, 49.706 Diario Oficial, 24 de noviembre de 2015. Disponible en: http://www.secretariasenado.gov.co/senado/basedoc/ley_1769_2015.html

Colombia, Ley 1815 de 2016, por la cual se decreta el presupuesto de rentas y recursos de capital y ley de apropiaciones para la vigencia fiscal del 1 de enero al 31 de diciembre de 2017, 50.080 Diario Oficial, 7 de diciembre de 2016. Disponible en: http://www.secretariasenado.gov.co/senado/basedoc/ley_1815_2016.html

Colombia, Ley 1819 de 2016, por medio de la cual se adopta una reforma tributaria estructural, se fortalecen los mecanismos para la lucha contra la evasión y la elusión fiscal, y se dictan otras disposiciones, 50.101 Diario Oficial, 29 de diciembre de 2016. Disponible en: http://www.secretariasenado.gov.co/senado/ basedoc/ley_1819_2016.html

Colombia, Comisión Nacional de Precios de Medicamentos, CNPM, Circular 04 de 2006, 1 de septiembre de 2006. Disponible en: http://www.sic.gov.co/sites/default/ files/files/circular4_2006.pdf

Colombia, Consejo Nacional de Seguridad Social en Salud, CNSSS, Acuerdo 260 de 2004, por el cual se define el régimen de pagos compartidos y cuotas moderadoras dentro del Sistema General de Seguridad Social en Salud, 45.474 Diario Oficial, 27 de febrero de 2004. Disponible en: http://www.alcaldiabogota.gov.co/sisjur/ normas/Norma1.jsp?i=32036

Colombia, Ministerio de la Protección Social, Resolución 2565 de 2007, por la cual se adoptan unas determinaciones en relación con la cuenta de alto costo, 46.706 
Diario Oficial, 31 de julio de 2007. Disponible en: https://www.minsalud.gov.co/ sites/rid/Lists/BibliotecaDigital/RIDE/DE/DIJ/resolucion-2565-2007.pdf

Colombia, Ministerio de la Protección Social, Resolución 003099 de 2008, por la cual se reglamentan los Comités Técnico-Científicos y se establece el procedimiento de recobro ante el Fondo de Solidaridad y Garantía, Fosyga, por concepto de suministro de medicamentos, servicios médicos y prestaciones de salud no incluidos en el Plan Obligatorio de Salud, POS, autorizados por Comité Técnico-Científico y por fallos de tutela, 47.088 Diario Oficial, 21 de agosto de 2008. Disponible en: http://www.alcaldiabogota.gov.co/sisjur/normas/Norma1. jsp?i=32044

Colombia, Ministerio de la Protección Social, Resolución 3974 de 2009, por la cual se adoptan unas determinaciones en relación con la Cuenta de Alto Costo, 47.516 Diario Oficial, 28 de octubre de 2009. Disponible en: https://docs.supersalud.gov. co/PortalWeb/Juridica/OtraNormativa/R_MPS_3974_2009.pdf

Colombia, Ministerio de la Protección Social, Resolución 548 de 2010, por la cual se reglamentan los Comités Técnico-Científicos, se establece el procedimiento de radicación, reconocimiento y pago de recobros ante el Fondo de Solidaridad y Garantía-Fosyga-y se dictan otras disposiciones aplicables durante el período de transición de que trata el artículo 19 del Decreto Legislativo 128 de 2010, 47.621 Diario Oficial, 12 de febrero de 2010. Disponible en: http://www.alcaldiabogota. gov.co/sisjur/normas/Norma1.jsp?i=38915\#27

Colombia, Ministerio de Salud y Protección Social, Resolución 003977 del 9 de septiembre de 2011, por la cual se adiciona el presupuesto del mecanismo único de recaudo y giro de los recursos que financian y cofinancian la Unidad de Pago por Capitación del Régimen Subsidiado para la vigencia fiscal de 2013. Disponible en: https://www.minsalud.gov.co/Normatividad_Nuevo/Resoluci $\% \mathrm{C} 3 \% \mathrm{~B} 3 \mathrm{n} \% 20$ $3977 \% 20 \mathrm{de} \% 202013 . p d f$

Colombia, Ministerio de la Protección Social, Resolución 458 de 2013, por la cual se unifica el procedimiento de recobro ante el Fondo de Solidaridad y Garantía (Fosyga) y se dictan otras disposiciones, 48.712 Diario Oficial, 22 de febrero de 2013. Disponible en: http://www.alcaldiabogota.gov.co/sisjur/normas/Norma1. jsp?i=52011

\section{Jurisprudencia colombiana}

Colombia, Consejo de Estado, Sala de lo Contencioso Administrativo, Sección Quinta, Radicación 52001-23-33-000-2013-00377-01, 10 de abril de 2014, consejero ponente Alberto Yepes-Barreiro. Disponible en: https://docs.supersalud.gov. co/PortalWeb/Juridica/Sentencias/CE\%20SCA\%20SECV\%2052001-23-33-0002013-00377-01(AC).pdf

Colombia, Consejo de Estado, Sala de lo Contencioso Administrativo, Sección Quinta, Radicación 11001-03-15-000-2014-04332-00, 5 de febrero de 2015, consejera ponente Lucy Jeannette Bermúdez-Bermúdez. Disponible en: http:// consejodeestado.gov.co/documentos/sentencias/11001031500020140433200.pdf

Colombia, Corte Constitucional, Sentencia C-383-99, 27 de mayo de 1999, magistrado ponente Alfredo Beltrán-Sierra. Disponible en: http://www.corteconstitucional. 
gov.co/relatoria/1999/c-383-99.htm

Colombia, Corte Constitucional, Sentencia C-700-99, 16 de septiembre de 1999, magistrado ponente José Gregorio Hernández-Galindo. Disponible en: http:// www.corteconstitucional.gov.co/relatoria/1999/c-700-99.htm

Colombia, Corte Constitucional, Sentencia C-747-99, 6 de octubre de 1999, magistrado ponente Alfredo Beltrán-Sierra. Disponible en: http://www.corteconstitucional. gov.co/relatoria/1999/c-747-99.htm

Colombia, Corte Constitucional, Sentencia C-316-08, 9 de abril de 2008, magistrado ponente Jaime Córdoba-Triviño. Disponible en: http://www.corteconstitucional. gov.co/relatoria/2008/c-316-08.htm

Colombia, Corte Constitucional, Sentencia C-463-08, 14 de mayo de 2008, magistrado ponente Jaime Araujo-Rentería. Disponible en: http://www.corteconstitucional. gov.co/relatoria/2008/c-463-08.htm

Colombia, Corte Constitucional, Sentencia C-122-12, 22 de febrero de 2012, magistrado ponente Jorge Ignacio Pretelt-Chaljub. Disponible en: http://www. corteconstitucional.gov.co/relatoria/2012/C-122-12.htm

Colombia, Corte Constitucional, Sentencia C-313-14, 29 de mayo de 2014, magistrado ponente Gabriel Eduardo Mendoza-Martelo. Disponible en: http://www. corteconstitucional.gov.co/relatoria/2014/c-313-14.htm

Colombia, Corte Constitucional, Sentencia SU-480-97, 25 de septiembre de 1997, magistrado ponente Alejandro Martínez-Caballero. Disponible en: http://www. corteconstitucional.gov.co/relatoria/1997/su480-97.htm

Colombia, Corte Constitucional, Sentencia SU-559-97, 6 de noviembre de 1997, magistrado ponente Eduardo Cifuentes-Muñoz. Disponible en: http://www. corteconstitucional.gov.co/relatoria/1997/su559-97.htm

Colombia, Corte Constitucional, Sentencia SU-562-99, 4 de agosto de 1999, magistrado ponente Alejandro Martínez-Caballero. Disponible en: http://www. corteconstitucional.gov.co/relatoria/1999/su562-99.htm

Colombia, Corte Constitucional, Sentencia SU-819-99, 20 de octubre de 1999, magistrado ponente Álvaro Tafur-Galvis. Disponible en: http://www.corteconstitucional. gov.co/relatoria/1999/su819-99.htm

Colombia, Corte Constitucional, Sentencia SU-090-00, 2 de febrero de 2000, magistrado ponente Eduardo Cifuentes-Muñoz. Disponible en: http://www. corteconstitucional.gov.co/relatoria/2000/su090-00.htm

Colombia, Corte Constitucional, Sentencia T-406-92, 5 de junio de 1992, magistrado ponente Ciro Angarita-Barón. Disponible en: http://www.corteconstitucional. gov.co/relatoria/1992/t-406-92.htm

Colombia, Corte Constitucional, Sentencia T-484-92, 11 de agosto de 1992, magistrados ponentes Simón Rodríguez-Rodríguez, Jaime Sanín-Greiffenstein. Disponible en: http://www.corteconstitucional.gov.co/relatoria/1992/t-484-92.htm

Colombia, Corte Constitucional, Sentencia T-505-92, 28 de agosto de 1992 , magistrado ponente Eduardo Cifuentes-Muñoz. Disponible en: http://www. corteconstitucional.gov.co/relatoria/1992/t-505-92.htm 
Colombia, Corte Constitucional, Sentencia T-522-92, 19 de septiembre de 1992, magistrado ponente Alejandro Martínez-Caballero. Disponible en: http://www. corteconstitucional.gov.co/relatoria/1992/t-522-92.htm

Colombia, Corte Constitucional, Sentencia T-533-92, 23 de septiembre de 1992, magistrado ponente Eduardo Cifuentes-Muñoz. Disponible en: http://www. corteconstitucional.gov.co/relatoria/1992/t-533-92.htm

Colombia, Corte Constitucional, Sentencia T-571-92, 26 de octubre de 1992, magistrado ponente Jaime Sanín-Greiffenstein. Disponible en: http://www. corteconstitucional.gov.co/relatoria/1992/t-571-92.htm

Colombia, Corte Constitucional, Sentencia T-116-93, 26 de marzo de 1993, magistrado ponente Hernando Herrera-Vergara. Disponible en: http://www. corteconstitucional.gov.co/relatoria/1993/t-116-93.htm

Colombia, Corte Constitucional, Sentencia T-388-93, 15 de septiembre de 1993, magistrado ponente Hernando Herrera-Vergara. Disponible en: http://www. corteconstitucional.gov.co/relatoria/1993/t-388-93.htm

Colombia, Corte Constitucional, Sentencia T-030-94, 2 de febrero de 1994, magistrado ponente Alejandro Martínez Caballero. Disponible en: http://www. corteconstitucional.gov.co/relatoria/1994/t-030-94.htm

Colombia, Corte Constitucional, Sentencia T-192-94, 20 de abril de 1994, magistrado ponente José Gregorio Hernández-Galindo. Disponible en: http://www. corteconstitucional.gov.co/relatoria/1994/t-192-94.htm

Colombia, Corte Constitucional, Sentencia T-271-95, 23 de junio de 1995, magistrado ponente Alejandro Martínez-Caballero. Disponible en: http://www. corteconstitucional.gov.co/relatoria/1995/t-271-95.htm

Colombia, Corte Constitucional, Sentencia T-383-95, 31 de agosto de 1995, magistrado ponente Alejandro Martínez-Caballero. Disponible en: http://www. corteconstitucional.gov.co/relatoria/1995/t-383-95.htm

Colombia, Corte Constitucional, Sentencia T-237-96, 28 de mayo de 1996, magistrado ponente Carlos Gaviria-Díaz. Disponible en: http://www.corteconstitucional. gov.co/relatoria/1996/t-237-96.htm

Colombia, Corte Constitucional, Sentencia T-068-98, 5 de marzo de 1998, magistrado ponente Alejandro Martínez-Caballero. Disponible en: http://www. corteconstitucional.gov.co/relatoria/1998/t-068-98.htm

Colombia, Corte Constitucional, Sentencia T-153-98, 28 de abril de 1998, magistrado ponente Eduardo Cifuentes-Muñoz. Disponible en: http://www. corteconstitucional.gov.co/relatoria/1998/t-153-98.htm

Colombia, Corte Constitucional, Sentencia T-760-98, 7 de diciembre de 1998, magistrado ponente Antonio Barrera-Carbonell. Disponible en: http://www. corteconstitucional.gov.co/relatoria/1998/t-760-98.htm

Colombia, Corte Constitucional, Sentencia T-626-00, 30 de mayo de 2000, magistrado ponente Álvaro Tafur-Galvis. Disponible en: http://www.corteconstitucional. gov.co/relatoria/2000/T-626-00.htm

Colombia, Corte Constitucional, Sentencia T-1204-00, 14 de septiembre de 2000, 
magistrado ponente Alejandro Martínez-Caballero. Disponible en: http://www. corteconstitucional.gov.co/relatoria/2000/t-1204-00.htm

Colombia, Corte Constitucional, Sentencia T-1695-00, 7 de diciembre de 2000, magistrado ponente Martha Victoria Sáchica-Méndez. Disponible en: http:// www.corteconstitucional.gov.co/relatoria/2000/t-1695-00.htm

Colombia, Corte Constitucional, Sentencia T-1081-01, 11 de octubre de 2001, magistrado ponente Marco Gerardo Monroy-Cabra. Disponible en: http://www. corteconstitucional.gov.co/relatoria/2001/t-1081-01.htm

Colombia, Corte Constitucional, Sentencia T-325-02, 2 de mayo de 2002, magistrado ponente Jaime Araújo-Rentería. Disponible en: http://www.corteconstitucional. gov.co/relatoria/2002/t-325-02.htm

Colombia, Corte Constitucional, Sentencia T-025-04, 22 de enero de 2014, magistrado ponente Manuel José Cepeda-Espinosa. Disponible en: http://www. corteconstitucional.gov.co/relatoria/2004/t-025-04.htm

Colombia, Corte Constitucional, Sentencia T-736-04, 5 de agosto de 2004, magistrado ponente Clara Inés Vargas-Hernández. Disponible en: http://www. corteconstitucional.gov.co/relatoria/2004/t-736-04.htm

Colombia, Corte Constitucional, Sentencia T-1216-04, 3 de diciembre de 2004, magistrado ponente Manuel José Cepeda-Espinosa. Disponible en: http://www. corteconstitucional.gov.co/relatoria/2004/t-1216-04.htm

Colombia, Corte Constitucional, Sentencia T-016-07, 22 de enero de 2007, magistrado ponente Humberto Antonio Sierra-Porto. Disponible en: http://www. corteconstitucional.gov.co/relatoria/2007/t-016-07.htm

Colombia, Corte Constitucional, Sentencia T-648-07, 17 de agosto de 2007, magistrada ponente Clara Inés Vargas-Hernández. Disponible en: http://www. corteconstitucional.gov.co/relatoria/2007/t-648-07.htm

Colombia, Corte Constitucional, Sentencia T-1007-07, 22 de noviembre de 2007, magistrada ponente Clara Inés Vargas-Hernández. Disponible en: http://www. corteconstitucional.gov.co/relatoria/2007/t-1007-07.htm

Colombia, Corte Constitucional, Sentencia T-125-08, 14 de febrero de 2008, magistrado ponente Nilson Pinilla-Pinilla. Disponible en: http://www.corteconstitucional. gov.co/relatoria/2008/t-125-08.htm

Colombia, Corte Constitucional, Sentencia T-139-08, 15 de febrero de 2008, magistrada ponente Clara Inés Vargas-Hernández. Disponible en: http://www. corteconstitucional.gov.co/relatoria/2008/t-139-08.htm

Colombia, Corte Constitucional, Sentencia T-144-08, 15 de febrero de 2008, magistrada ponente Clara Inés Vargas-Hernández. Disponible en: http://www. corteconstitucional.gov.co/relatoria/2008/t-144-08.htm

Colombia, Corte Constitucional, Sentencia T-473-08, 15 de mayo de 2008, magistrada ponente Clara Inés Vargas-Hernández. Disponible en: http://www. corteconstitucional.gov.co/relatoria/2008/t-473-08.htm

Colombia, Corte Constitucional, Sentencia T-517-08, 22 de mayo de 2008, magistrada ponente Clara Inés Vargas-Hernández. Disponible en: http://www. 
corteconstitucional.gov.co/relatoria/2008/t-517-08.htm

Colombia, Corte Constitucional, Sentencia T-760-08, 31 de julio de 2008, magistrado ponente José Manuel Cepeda-Espinosa. Disponible en: http://www. corteconstitucional.gov.co/relatoria/2015/t-760-08.htm

Colombia, Corte Constitucional, Sentencia T-818-08, 21 de agosto de 2008, magistrada ponente Clara Inés Vargas-Hernández. Disponible en: http://www. corteconstitucional.gov.co/relatoria/2008/t-818-08.htm

Colombia, Corte Constitucional, Sentencia T-124-09, 24 de febrero de 2009, magistrado ponente Humberto Antonio Sierra-Porto. Disponible en: http://www. corteconstitucional.gov.co/relatoria/2009/t-124-09.htm

Colombia, Corte Constitucional, Sentencia T-432-09, 1 de julio de 2009, magistrado ponente Humberto Nilson Pinilla-Pinilla. Disponible en: http://www. corteconstitucional.gov.co/relatoria/2009/t-432-09.htm

Colombia, Corte Constitucional, Sentencia T-922-09, 9 de diciembre de 2009, magistrado ponente Jorge Iván Palacio-Palacio. Disponible en: http://www. corteconstitucional.gov.co/relatoria/2009/t-922-09.htm

Colombia, Corte Constitucional, Sentencia T-199-10, 23 de marzo de 2010, magistrado ponente Humberto Antonio Sierra-Porto. Disponible en: http://www. corteconstitucional.gov.co/relatoria/2010/t-199-10.htm

Colombia, Corte Constitucional, Sentencia T-320-11, 4 de mayo de 2011, magistrado ponente Jorge Iván Palacio-Palacio. Disponible en: http://www. corteconstitucional.gov.co/relatoria/2011/t-320-11.htm

Colombia, Corte Constitucional, Sentencia T-017-13, 25 de enero de 2013, magistrado ponente Luis Ernesto Vargas-Silva. Disponible en: http://www. corteconstitucional.gov.co/relatoria/2013/t-017-13.htm

Colombia, Corte Constitucional, Sentencia T-611-14, 25 de agosto de 2014, magistrado ponente Jorge Iván Palacio-Palacio. Disponible en: http://www. corteconstitucional.gov.co/relatoria/2014/t-611-14.htm

\section{Medios}

A un año de haber sido sancionada, la Ley Estatutaria de Salud aún no nace, Opinión \& Salud, Revista Digital (15 de febrero de 2016). Disponible en: http://www. opinionysalud.com/a-un-ano-de-ser-sancionada-la-ley-estatutaria-de-saludaun-no-nace/

Bardey, David, Los precios de los medicamentos en Colombia, Blogoeconomia (27 de mayo de 2013). Disponible en: http://lasillavacia.com/elblogueo/blog/los-preciosde-los-medicamentos-en-colombia-por-david-bardey, https://goo.gl/C1YrGX

Dos años después de la Ley Estatutaria la crisis de la salud sigue igual, Opinión \& Salud, Revista Digital (17 de febrero de 2017). Disponible en: http://www.opinionysalud. com/ley-estatutaria-salud-ministro-gaviria/

Economía, Lista comisión que fijará precios de medicamentos, El Tiempo (2 de mayo de 2016). Disponible en: http://www.eltiempo.com/archivo/documento/CMS- 
16579583

El costo que tiene la diabetes, Portafolio (Tendencias, 2 de octubre de 2016). Disponible en: http://www.portafolio.co/tendencias/costo-diabetes-50680

El viacrucis del paciente de alto costo, Revista Semana (Tratamiento, 13 de febrero de 2016). Disponible en: https://goo.gl/zTsiwU

Fajardo, Luis, ¿Por qué Colombia paga los medicamentos más caros de América Latina?, BBC Mundo (10 de marzo de 2015). Disponible en: http://www.bbc.com/mundo/ noticias/2015/03/150220_economia_medicamentos_colombia_lf?ocid=socialflow_ twitter, https://goo.gl/DzumpE

Qué va a pasar sin el POS, Revista Semana (Salud, 17 de febrero de 2017). Disponible en: http://www.semana.com/vida-moderna/articulo/pos-es-sustituido-por-unnuevo-mecanismo/515869

Redacción Salud, Cada cinco minutos hay una nueva tutela de salud en el país, El Tiempo (4 de septiembre de 2013). Disponible en: http://www.eltiempo.com/archivo/ documento/CMS-13045163

\section{Direcciones web}

Conozca qué es la unidad de pago por capitación. Disponible en: http://goo.gl/9Hpzht

Ministerio de Hacienda, Boletín 110 (Bogotá, 2015). Disponible en línea: http://www. minhacienda.gov.co/HomeMinhacienda/ShowProperty;jsessionid=xQsphY0t WC-QOGzurHsKcsY23kNkoD17EgX1iMvUmNsM613OcQJ5!508618735?nod $\mathrm{eId}=\% 2 \mathrm{FOCS} \% 2 \mathrm{FMIG} \_41322604 . \mathrm{PDF} \% 2 \mathrm{~F} \% 2 \mathrm{FidcPrimaryFile \& revision=lat}$ estreleased

Ministerio de Hacienda, Boletín 176 (Bogotá, 2016). Disponible en línea: http://www. minhacienda.gov.co/HomeMinhacienda/ShowProperty?nodeId=/OCS/P_ MHCP_WCC-059064//idcPrimaryFile\&revision=latestreleased

Ministerio de Salud, Regulación de precios de medicamentos. Disponible en: https://www. minsalud.gov.co/salud/MT/Paginas/medicamentos-regulacion-precios.aspx

Ministerio de Salud y Protección Social, ABC de la unificación del POS (Boletín de Prensa 186 de 2012, 16 de julio de 2012). Disponible en: https://www.minsalud. gov.co/Paginas/ABC $\% 20 \mathrm{de} \% 201 \mathrm{a} \% 20$ Unificaci $\% \mathrm{C3} \% \mathrm{~B} 3 \mathrm{n} \% 20 \mathrm{del} \% 20 \mathrm{POS}$.aspx

Ministerio de Salud y Protección Social, Cifras financieras del sector salud - Boletín 11 (Bogotá, julio-agosto de 2015). Disponible en: https://www.minsalud.gov.co/sites/ $\mathrm{rid} /$ Lists/BibliotecaDigital/RIDE/VP/FS/cifras-financieras-del-sector-salud $\% 20$ -boletin-numero-11.pdf

Montes, Mateo, Historial Pensiones Instituto de Seguros Sociales (ISS) (16 de julio de 2015). Disponible en: http://www.colconectada.com/historial-pensionesinstituto-de-seguros-sociales-iss/

Tipos de régimen de salud en Bogotá. Disponible en: http://institutodeestudiosurbanos. info/endatos/0200/02-020-salud/docs/TRSB.pdf 


\section{Entrevistas, derechos de petición}

Entrevista al doctor Mauricio Alfredo Plazas-Vega, con uno de los estudiantes del proyecto de investigación Progresividad del gasto público social y su impacto sobre el derecho a la salud (Bogotá, 21 de octubre de 2014).

Ministerio de Salud y Protección Social, Respuesta al derecho de petición 201433201779521, del 15 de diciembre de 2014, del Ministerio de Salud, con ocasión al derecho de petición instaurado por la profesora Clara Viviana Plazas-Gómez, de la Facultad de Jurisprudencia de la Universidad del Rosario, radicado interno AJH001, del 2 de diciembre de 2014 (Bogotá, 2015). 
